\title{
Taking critical services to the home: Scaling-up home-based maternal and postnatal care, including family planning, through community midwifery in Kenya
}

Annie Mwangi

Population Council

Charlotte E. Warren

Population Council

Follow this and additional works at: https://knowledgecommons.popcouncil.org/departments_sbsr-rh

Part of the Demography, Population, and Ecology Commons, International Public Health Commons, Maternal and Child Health Commons, and the Women's Health Commons

How does access to this work benefit you? Let us know!

\section{Recommended Citation}

Mwangi, Annie and Charlotte E. Warren. 2008. "Taking critical services to the home: Scaling-up homebased maternal and postnatal care, including family planning, through community midwifery in Kenya," FRONTIERS Final Report. Washington, DC: Population Council. 


\title{
Taking Critical Services to the Home: Scaling-up Home-based Maternal and Postnatal Care, including Family Planning, through Community Midwifery in Kenya
}

\author{
Frontiers in Reproductive Health, Population Council \\ Annie Mwangi \\ Charlotte Warren
}

July 2008

This study is made possible by the generous support of the American people through the United States Agency for International Development (USAID) under the terms of Cooperative Agreement Number HRN-A-00-98-00012-00 and In-house project 5800 53111. The contents are the responsibility of FRONTIERS and do not necessarily reflect the views of USAID or the United States Government. 


\section{SUMMARY}

Increasing access to safe delivery and family planning services within rural communities increases the opportunities for women to have positive outcomes for their pregnancies as well as to plan and achieve their desired family size. With support from USAID, the Population Council's Frontiers in Reproductive Health (FRONTIERS) project supported the scaling up of a community-based model in Kenya that enabled women to give birth safely at home or be referred to a hospital when attended by a self-employed skilled midwife living in the community. Originally piloted through a demonstration project implemented by the Population Council with DFID support in Western Province, FRONTIERS assisted the Kenyan Ministry of Health $(\mathrm{MOH})$ to identify an expanded package of safe motherhood services, including postpartum family planning, which could be provided routinely by these 'community midwives' living and working from home with minimal supervision and supply of commodities from the $\mathrm{MOH}$. Guidelines and training materials for community midwives were developed and mechanisms for linkages with existing $\mathrm{MOH}$ systems at district level strengthened. Four districts (Mount Elgon, Bungoma, Lugari and Butere Mumias) in Western province were selected for scale up of the approach.

Sixty community midwives (CMs) were oriented in May 2007 in essential obstetric and newborn care skills as well as family planning; recognition and management of complications were also covered. Cross-cutting topics included infection prevention, interpersonal communication, community involvement and record keeping. All CMs completed a two- three week residential assignment in a busy maternity unit where they were observed carrying out a number of essential procedures, the outcomes of which were recorded in a log book and certified by the facility's senior midwife. They then received a certificate jointly signed by the Head of Division of Reproductive Health and the Registrar of the Nursing Council of Kenya, and were given a delivery kit and essential supplies to enable them to start providing antenatal, delivery, postpartum and family planning services in their community.

To strengthen the sustainability of this approach FRONTIERS engaged a microfinance NGO to develop a training curriculum on basic business skills and financial literacy, and encouraged the CMs to form clusters or informal associations so that they could be trained in business skills. Following these interventions, CMs proved more likely to make a profit and succeed in being reimbursed for the services rendered.

Community midwifery has contributed to increasing the proportion of women assisted by skilled attendants during birth in the four districts, amounting to just under half of all skilled attended births in the districts (6.1 percent compared to the 13.2 percent facility birth rate). Although the skilled birth attendant rate in these districts is well below the national average of 42 percent, there has been a steady increase in the proportion of attended deliveries since CMs were introduced in 2005. The districts have also reported an increase in postnatal assessments in the first 48 hours and increase in immunization coverage. 
It is anticipated that there will be a similar rise in the number of women able to receive FP commodities from the CMs since the introduction of this component in 2007. In one district, for example, only six months after their training the CMs were already providing one tenth of all injectables and one fifth of all contraceptive pills distributed in the district.

Many women and their families have requested additional services from the CM that are outside their current mandate; some of these services could feasibly be provided by CMs, for example, testing for HIV and provision of ARVs for PMTCT; treatment of minor illnesses particularly in infants and young children; and provision of long-acting methods of FP. Whether and how to expand the mandate of the CM model without compromising safety and the quality of care is a challenge that needs to be addressed through further operations research.

This experience with scaling up the model throughout four districts of Western Province has demonstrated that the community midwifery approach in Kenya is feasible and acceptable to the women, the community midwives themselves and to the $\mathrm{MOH}$ and is effective in increasing the proportion of women having a delivery by a skilled attendant and in increasing access to FP methods. The formation of the clusters and networks, a strong partnership with the public health care system, and technical updates to strengthen knowledge and skills and the training in business skills were key components in ensuring the successful scale-up at district level. Although challenges remain, notably in ensuring that the CMs are able to be compensated sufficiently to both cover the costs of providing the services and motivating their continuation, the $\mathrm{MOH}$ has expressed its commitment to expanding access to essential reproductive health care at the community level through the community midwife approach. Recommendations for future implementation of the model include:

Support skills development for maintenance of quality of care: Professional bodies such as the nursing council, the professional associations and the Ministry of Health need to establish systems for ensuring continued professional competency for quality health care in the community. This could include specified hours for continuous professional development per year, theory and clinical practice included.

Support the community midwives to achieve financial sustainability: For this model to continue within the public health system, a monthly stipend would enable midwives to replenish supplies and allow them to offer services to low-income clients who could not pay the full service fees. Alternatively, it would be important to explore ways of developing alternative health financing models that could support this model, such as the Output Based Aid (OBA) approach currently being pilot-tested by the Kenyan Government, or a social franchising model as is being undertaken with private midwives in other countries.

Strengthen the business skills: all CMs must be provided with basic business skills to build their capacity in running the services, regardless of the health financing model through which they are supported. In addition, DHMTs should link with local offices of microfinance enterprises to support the CMs' networks in developing their business skills and savings.

Strengthen and support the linkages between the CM and the formal health sector through the DHMT: The CM is a potentially important source of information about health status and services at the community level for the health care system. To achieve this, appropriate tools for data collection in the community are important and the MOH would benefit tremendously by developing and providing such tools to collect these data. 
The $\mathrm{MOH}$ launched the $\mathrm{CM}$ approach through a speech by the Assistant Minister in Western Province in October 2006, and distributed the CM Guidelines in mid-2007. The preliminary findings and lessons learned from this project were communicated to key stakeholders in April 2008. Following the findings of the DFID-supported pilot project, a number of development partners had already supported training of CMs in other parts of the country; to date, four UNFPA-supported districts (Nyandarua in Central Province, Mwingi in Eastern Province and Kilifi and Taita Taveta districts in Coast Province) have trained over $70 \mathrm{CMs}$ in the last 18 months. With technical assistance from FRONTIERS, Maragua district in Central Province trained 27 midwives in March 2008. The USAID-funded APHIA II project in Coast Province trained 40 community midwives from Lamu, Malindi, Kwale and Kilifi districts and the APHIA II project in Rift Valley province has trained twelve midwives from Kajiado and Loitokok districts, with further training planned for August 2008. The DFID-funded 'Essential Health Services' project is about to train 40 midwives in two districts in Nyanza Province. Lessons from this study have also been presented at several national and international workshops and conferences. 


\section{ABBREVIATIONS AND ACRONYMS}

$\begin{array}{ll}\text { ANC } & \text { Antenatal Care } \\ \text { ART } & \text { Antiretroviral Treatment } \\ \text { CM } & \text { Community Midwife } \\ \text { CHPS } & \text { Community based Health and Family Planning } \\ \text { DHS } & \text { Demographic Health Survey } \\ \text { DHMT } & \text { District Health Management Team } \\ \text { DPHN } & \text { District Public Health Nurse } \\ \text { DRH } & \text { Division of Reproductive Health } \\ \text { DRHST } & \text { District Reproductive Health Supervision and Training team } \\ \text { EOC } & \text { Emergency Obstetric Care } \\ \text { HEW } & \text { Health Extension Worker } \\ \text { HIV } & \text { Human Immunodeficiency Virus } \\ \text { IUCD } & \text { Intra Uterine Contraceptive Device } \\ \text { KCOC } & \text { Kenya Council of Clinical Officers } \\ \text { KEPH } & \text { Kenya Essential Package for Health } \\ \text { KDHS } & \text { Kenya Demographic and Health Survey } \\ \text { KOGS } & \text { Kenya Obstetric and Gynaecological Society } \\ \text { LAM } & \text { Lactational Amenorrhea Method } \\ \text { LSS } & \text { Life Saving Skills } \\ \text { MCH } & \text { Maternal Child Health } \\ \text { MNH } & \text { Maternal and Newborn Health } \\ \text { MOH } & \text { Ministry of Health } \\ \text { MPDB } & \text { Medical Practitioners and Dentists Board } \\ \text { NCK } & \text { Nursing Council of Kenya } \\ \text { NNAK } & \text { National Nurse Association of Kenya } \\ \text { NHSSP } & \text { National Health Sector Strategic Plan } \\ \text { PHMT } & \text { Provincial Health Management Team } \\ \text { PMTCT } & \text { Prevention of Mother to Child Transmission } \\ \text { PNC } & \text { Postnatal Care } \\ \text { Provincial Reproductive Health Supervision and Training Team } & \text { Reproductive Health } \\ \text { RHDitherhood Demonstration Project } \\ \text { Safe Mttendants }\end{array}$




\section{CONTENTS}

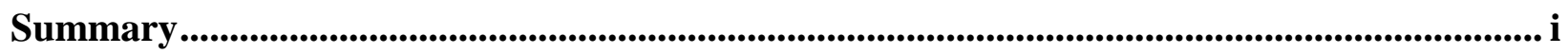

Recommendations ...............................................................................Error! Bookmark not defined.

Utilization of research findings..........................................................Error! Bookmark not defined.

Abbreviations and Acronyms .................................................................................................. iv

Acknowledgments ................................................................................................................................. vi

Introduction ............................................................................................................................... 1

Justification ............................................................................................................................................. 4

Objectives........................................................................................................................................... 5

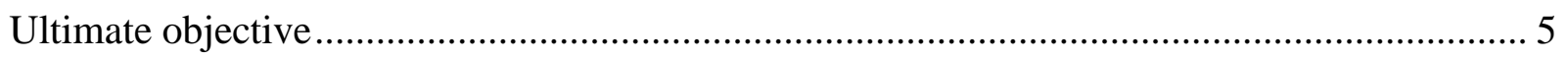

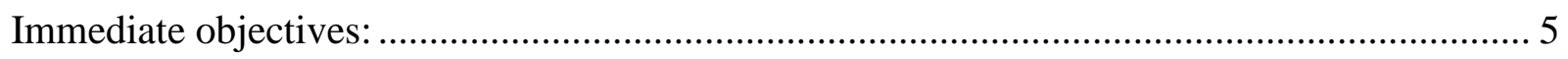

IMPLEMENTATION PROCESS ..................................................................................... 6

Recruitment and characteristics of Community Midwives....................................................... 7

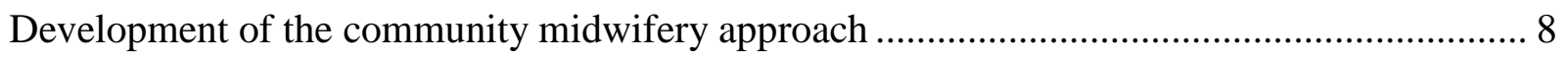

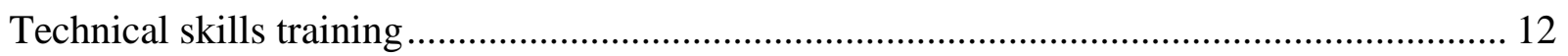

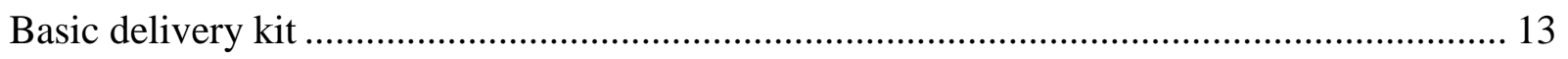

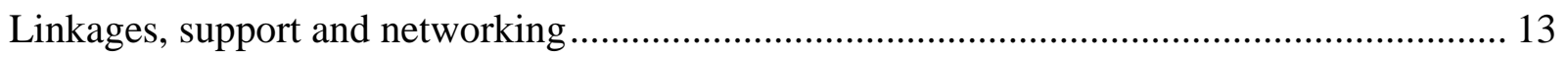

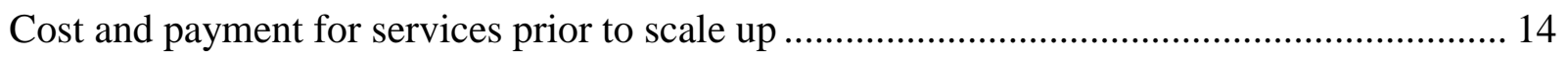

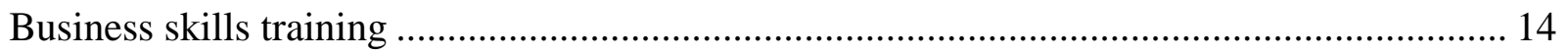

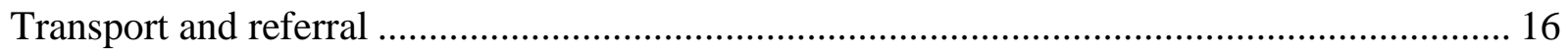

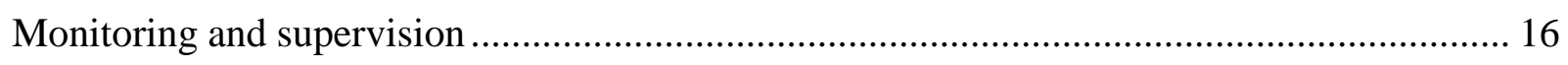

Legitimatizing community midwifery within the Kenya $\mathrm{MOH}$.............................................. 17

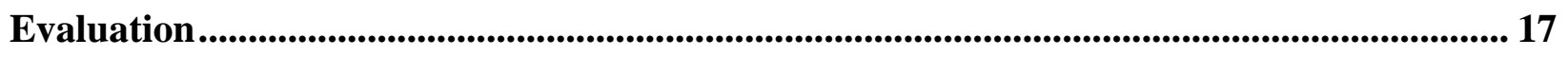

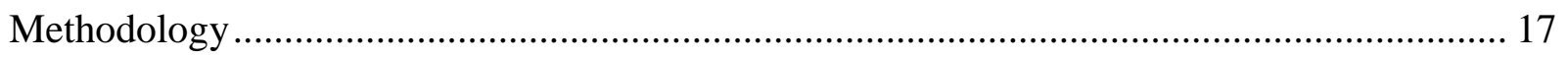

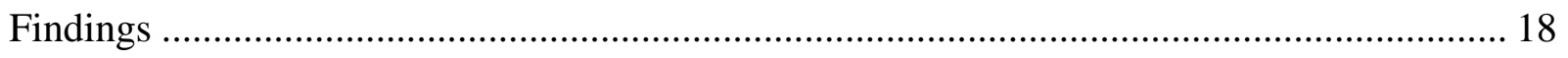

Financial sustainability of the community midwifery approach ……..................................... 21

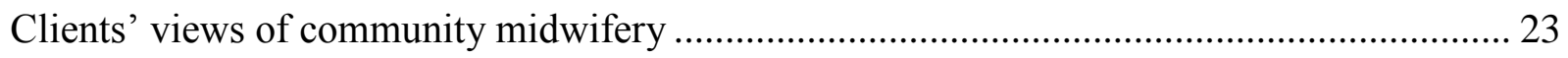

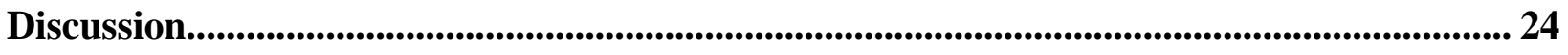

Recommendations ..................................................................................................................................... 26

Dissemination and utilization of findings ....................................................................................... 26

References.................................................................................................................................................. 27

Annex 1: Process for implementing the community midwifery model..................................... 29

Annex 2: Sample Business Plan for community Midwives ............................................................ 30

Annex 3: Monthly Summary Reporting Form: Community Midwifery_Services: .................. 35 


\section{ACKNOWLEDGMENTS}

We would like to thank those who made this scale up of community midwifery approach possible. Particular appreciation goes to the Head of the Department of Reproductive Health, Ministry of Health, Dr Josephine Kibaru, Chief Nurse Mr. Chris Rakuom, and Program Officer Charity Ndwiga. Their belief in the approach is demonstrated by the success of the project and in the increase in the number of pregnant women who now have access to skilled care at delivery. We would also like to thank the Nursing Council of Kenya for supporting the development of the certification process. The project is also deeply indebted to Professor Joseph Karanja from the Department of Obstetrics and Gynaecology at the University of Nairobi and the Kenya Obstetric and Gynaecological Society (KOGS), and Mrs Ojanga from the Midwifery Chapter of the National Nurses Association of Kenya.

Thanks go to all the pregnant women and postpartum women who participated in the study. Special recognition goes to the community midwives whose hard work and commitment contributed enormously to increasing skilled care at birth.

We would also like to recognize the financial support from United States Agency for International Development (USAID). 


\section{INTRODUCTION}

Evidence from a number of studies globally has shown a reduction in maternal and perinatal mortality when women have access to a skilled attendant providing a continuum of care from pregnancy, at birth and during the postpartum period. In Kenya, as in most of sub-Saharan Africa, although the majority (88\%) of women attend antenatal clinic at least once during pregnancy, more than half $(58 \%)$ give birth at home without any skilled assistance, and only $10 \%$ of those delivering at home receive any type of postpartum care. The maternal mortality ratio is 414 per 100,000 live births; the neonatal mortality rate is 33 per 1,000 live births, with the majority of deaths occurring within the first week of life. The infant mortality rate is 77 per 1,000 live births. The contraceptive prevalence rate has stagnated at 39\% and women have limited access to family planning during the immediate postpartum period. In Western Province the unmet need for family planning for spacing is $19 \%$ and for limiting is $13 \%$ (KDHS 2003).

Antenatal care and delivery: The main focus of strategies to increase skilled attendance in East and Southern Africa has been to provide comprehensive antenatal care and ensure that pregnant women plan and are prepared for the birth, and to strengthen the obstetric care provided within facilities. Although many facilities have improved the quality of care available, many women are still not using the facilities for childbirth and prefer to deliver in their own homes. In fact, some provinces in Kenya showed a downward shift in women using health facilities for giving birth between the DHS of 1998 and 2003 (Eastern Province from 49\% in 1998 to 38\% in 2003, Central Province from $69 \%$ to $67 \%$, Coast Province $33 \%$ down to $31 \%$ ). In Western Province the facility delivery rate increased from $27 \%$ to $28 \%$ over the same time period, but traditional birth attendants assisted $42 \%$ of women at their most recent delivery (KDHS 2003).

Postnatal care and family planning: Postnatal care programs are among the weakest of all reproductive and child health programs in sub Saharan Africa. The focus is primarily on the infant receiving immunizations at 6 weeks, with little attention being paid to early newborn or maternal care and to sexual behavior and fertility desires following delivery. Coordinating family planning with other health services during and after pregnancy can help improve reproductive health. The utilization of skilled midwives visiting the homes during the first week after birth has been recommended as an opportunity to identify complications in the mother and baby during a period which culturally prevents women from leaving their homes during the first month after birth. Home visits by professionals after birth show that healthy behaviors can be promoted and improved (Koblinsky 2005). For example, exclusive breast feeding, early breast feeding initiation leading to improved utilization of Lactational Amenorrhea Method (LAM), and either an effective transition from LAM to an alternate method at 6 months or early uptake of a long term family planning method, iron and folate supplements, hygienic care and immunizations, and knowledge of danger signs in mother and baby. The prevention of future unwanted pregnancies initiated during the early postpartum period as a strategy of reducing maternal morbidity and mortality is finding an increasing global focus but projects demonstrating the 'how to' within the community are still in their infancy.

Kenya's Health Policy: The Kenya Ministry of Health (MOH) second National Health Sector Strategic Plan 2005 - 2010 (NHSSP) shifts the emphasis from the 'burden of disease' to the promotion of the individual and community health. To implement this plan, the Kenya Essential 
Package for Health (KEPH) adopts a broad approach and focuses on the health needs of individuals through the six stages of the human health cycle. These life cycle stages are: pregnancy, delivery and newborn child (up to 2 weeks of age); early childhood ( 3 weeks to 5 years); late childhood (6 to 12 years); adolescence (13 to 24 years); adulthood ( 25 to 59 years) and elderly (60 years and over). The new Reproductive Health Policy (released in October 2007) outlines priority actions for maternal and neonatal health, which includes increasing access to skilled attendance for poor and 'hard to reach' women.

In October 2006 the Assistant Minister for Health (an obstetrician) launched the Community Midwifery Strategy in Bokoli Division, Bungoma District, Western Province. In his speech he recognized the need for strengthening linkages for health between community and facilities and to increase skilled attendants at birth. He applauded the efforts made in identifying alternative solutions to improving maternal and newborn care. There remains, however, need for more systematic documentation and assessment of the efficiencies and effectiveness of the approach, and the steps needed to create conditions for its scaling-up within the province and replication elsewhere.

The Division of Reproductive Health (DRH), in its annual business plan for 2006 -2007, outlined an objective to strengthen the community midwifery model pilot-tested in Western Province. Other organizations supporting the DRH in expanding community midwifery include:

- UNFPA in two districts;

- WHO in three districts;

- DFID-funded Essential Health Services (EHS) Program in two further districts.

The objectives of the USAID-funded APHIA II project complement the MOH NHSSP and its RH policy through expanding the availability of family planning, reproductive health, maternal and child health services with HIV/AIDS, and strengthening the linkages between community and facility health services.

Community midwifery pilot study in Western Province: The Population Council (funded by DFID) coordinated a province-wide Safe Motherhood Demonstration Project (SMDP) throughout Kenya's Western Province from 2000 - 2005. Although progress was made in many areas, towards the project's end many women $(71 \%)$ were still reluctant to give birth in health facilities. In some districts the facility based delivery rate is less than $10 \%$. In one district, however, where unemployed midwives were encouraged to assist women to give birth at home, there was a significant increase from $1 \%$ to $9 \%$ in the number of home assisted deliveries by skilled midwives over a two-year period. Based on this evidence, the SMDP pilot-tested the formal introduction of supporting retired/out of work midwives to strengthen the capacity of the community based private sector to provide primary-level health care and to attend to women giving birth at home in the communities in which they lived. Results from the pilot study showed that over 1,000 women in Western Province were visited in their homes and either delivered safely at home or referred to hospital between July 2005 and July 2006 (Rumbold and Warren 2006). Given that one district (Mt. Elgon) only delivered 137 women in health facilities during the whole of 2004 demonstrates the potential increase in skilled attendance at birth that community midwifery offers. 
All stakeholders, both at facilities and community based, were appreciative and supportive of this initiative because the so-called "community midwives" were perceived as qualified professionals operating within their communities with the requisite skills and equipment to provide quality services and to refer when necessary. All community midwives are selfemployed through charging fees for their services, i.e. they work in the private sector, but are also working in collaboration with the Ministry of Health. Some do have their own clinics, while others operate from their homes. All midwives assist women to give birth within the women's own homes. Each community midwife (CM) is formally attached to a public health facility. The CMs often assist the ANC clinics on busy days and have a good working relationship with the facility staff. The facility providers appreciate the extra support and welcome the increase in client attendance rates as a result of referrals from the $\mathrm{CM}$ on a range of issues from immunization to family planning. Some facilities are able to replenish the consumables required by the $\mathrm{CM}$ as they recognize the service that is now provided within the community. The midwives operate in clusters of three within a Division; however they are currently over stretched and the demand from the community to provide other services is high.

Other community based programs in maternal health: Although community based skilled delivery services have been introduced or strengthened successfully in some countries in Asia e.g. Egypt, Indonesia, Nepal, India, Bangladesh, there are few documented examples in sub Saharan Africa. In Ethiopia where skilled attendance at birth is around six percent, the Government has introduced a new cadre of health worker called the Health Extension Workers (HEW). These HEWs are trained for one year to provide a range of services within the community. They are expected to supervise and support Trained TBAs as well as assist at deliveries as well. The Community Partnerships for Safe Motherhood (CPSM) developed by PRIME/INTRAH prepares home birth attendants, pregnant women and their families in obstetric first aid. This is being implemented in India, and the Home-based LSS component of CPSM is being implemented in Guinea in collaboration with Save the Children's Child Survival Project.

These examples are in countries where there is a shortage of skilled health care providers and women have limited access to skilled midwives in rural areas and strategies to develop a new cadre to meet the demand are in place. Similarly, strategies to improve knowledge and practice of the TBAs and the families where there are few nurses are also important (Countries such as Guinea have few nurse/midwife training schools). In countries where there is a history of domiciliary midwifery, such as Kenya, Zimbabwe and Lesotho, and there are a sizable number of practicing private midwives and retired or out of work midwives, the opportunities exist to strengthen linkages and public-private partnerships to develop an additional strategy to increase the number of skilled attendants at birth.

Community based Health Planning and Services in Ghana: The Community based Health Planning and Services (CHPS) program ${ }^{1}$ in Ghana is based on the evidence generated by the Community Health and Family Planning (CHFP) experimental model at Navrongo, which has been developed and coordinated by Population Council from 1995. CHPS changes the focus of primary health care and FP services from clinical care to providing high-quality services at community and doorstep locations. The CHPS initiative represents an official response to

$1 \quad$ www.ghana-chps.org. 
develop a national model for community based health care, feasible means of sustaining the development of community services, and procedures for all districts in Ghana to share their experience with community service development with other District Health Management Teams. This national program of service delivery change is achieved by forging partnerships between health care providers and the communities they serve. Nurse/midwives are based within the community and are provided with a motorbike to visit clients in the homes and a small treatment room that has been built by the community. The Service Delivery Package includes treatment of minor ailments, FP, ANC, delivery and PNC, child welfare clinics, immunizations, counseling, school health, home visits, supervision of TBAs and volunteers. It has proved remarkably successful in increasing contraceptive use and in improving child survival.

Private practitioners: In Kenya, IntraHealth as a partner in the ACQUIRE Project, implemented a program to strengthen the capacity of the private sector to provide primary-level health care in Kenya. The concept is for carefully selected and empowered facilities to offer a high quality "basket of services" to community members who understand, appreciate and utilize these resources. The services offered include prevention of mother-to-child transmission (PMTCT) of HIV, voluntary counseling and testing, family planning and postabortion care. However home deliveries do not form part of this service.

\section{JUSTIFICATION}

Limited facility based deliveries and inadequate postnatal care and follow-up, and unmet need for family planning among women following delivery is not unique to Kenya; indeed, these are widely acknowledged problems in many sub-Saharan African countries. Results from this study will complement other FRONTIERS activities, including the forthcoming collaboration with WHO to revitalize CBD programs in countries with best examples and government commitment to community programs.

This Community Midwifery Strategy has wider implications beyond Kenya, as a potential strategy within WHO/AFRO's “Road Map for Accelerated Reduction in Maternal and Newborn Morbidity and Mortality" (February 2004), and the recent "Maputo Plan of Action of the Continental Policy Framework for SRH and Rights" (September 2006), which was signed by African governments. The community midwifery strategy was presented to the Reproductive Health Task Force for WHO/AFRO in October 2005 and at a WHO/AFRO meeting in February 2006 to discuss the essential competencies required for skilled attendants in the region.

Considerable interest was expressed in both meetings from many countries. Lessons will also be drawn from the highly successful Ghana Community based Health Planning and Services (CHPS) Program, with which this strategy has many similarities.

The Kenya MOH has clearly stated its interest in innovative mechanisms for involving the private sector and for enhancing community involvement in health, as described in the Kenya National Health Sector Strategic Plan 2005 - 2010. Within the national Reproductive Health Policy, strengthening community-facility linkages and focusing on improving access for hard to reach women are two priority areas, which will be informed by this project. The components of community midwifery were developed in accordance with WHO guidelines (WHO 2004). One major challenge faced in the CM pilot phase, however, was the lack of a standardized financing 
mechanism to reimburse the CMs' costs and motivate them financially. Community midwives are not employees of the government or any organization and they depend entirely on community members' ability to pay or otherwise compensate them for the services provided. In the presence of extreme poverty and poor business skills, financial problems contributed to the loss of five CMs from the pilot project. Their motivation was also affected by the uncertainty of limited funds made available to the CMs by the project to procure additional medical supplies, airtime and transport.

\section{OBJECTIVES}

\section{Ultimate objective}

To improve maternal, neonatal and infant health status through increasing the proportion of women delivering with a skilled attendant and receiving essential antenatal, postpartum, newborn care and family planning services.

\section{Immediate objectives:}

1. To assist the Ministry of Health to strengthen, institutionalize and scale up its community midwife strategy and services in four districts in Western Province, through:
a) Identifying a package of effective services (including postpartum FP) and activities that can be implemented routinely by self-employed midwives with minimal supervision from the $\mathrm{MOH}$.
b) Assisting the Ministry of Health to develop guidelines, standards and operational protocols for implementing the identified service package through self-employed community midwives.
c) Identifying mechanisms for linking self-employed midwives with existing $\mathrm{MOH}$ district level health systems.
d) Identifying potential networks of support and fee mechanisms that can be utilized to sustain the midwives independently of financial support from the $\mathrm{MOH}$.

2. To assess and describe the feasibility of implementing the community midwifery package of maternal, newborn and family planning services.

3. To document systematically and disseminate widely the lessons learned in sustaining and scaling up of successful CM interventions. 


\section{IMPLEMENTATION PROCESS}

For successful implementation of community midwifery, all levels of the national health system (national, provincial, district and community) have to play complementary and supportive roles. Good working relationships should be nurtured through all phases of program planning and implementation. The implementation process followed three phases (for more detail, see Annex 1):

- PHASE 1: Planning and start up:

- Rapid assessment of situation in the district;

- Reaching consensus with community, local administration and health facility staff

- Identification and selection of Community Midwives (CMs)

- PHASE 2: Introduction of interventions:

○ Training of CMs, clinical attachment, business skills development and procurement and supply of equipment

○ Follow up supervision

- $\quad$ PHASE 3: Scale up and sustainability:

○ Monitoring and evaluation and documentation

○ Sustainability mechanisms incorporated into district annual operational plans.

\section{Preparatory activities}

A team of three program officers from the DRH and FRONTIERS visited the Community Based Health Planning and Services program (CHPS) in Nkwanta, Ghana. CHPS was originally developed by the Population Council with funding from USAID and other donors as an approach for increasing access to reproductive health services through relocating full-time nurses to the community. As a successful model of mobilizing and supporting nurses to work within communities, which is now being scaled up throughout Ghana, CHPS provided a number of useful lessons to guide the Kenya team in revising and scaling up the community midwifery model. Site visits demonstrated key programmatic elements, including phased introduction of services, mapping and enumeration, community participation, nurse and volunteer training services, and strategic planning. The Kenya team was also oriented to practical aspects of community mobilization, engagement and support, building leadership, sustaining political commitment and service delivery in hard to reach communities.

As agreed with the Provincial Health Management Team (PHMT) and the Department of Reproductive Health (DRH), four districts were randomly selected for the scale up from the eight districts in Western Province. Two districts that offered comprehensive essential obstetric care services (Butere Mumias and Bungoma) and two that had basic essential obstetric care services only (Lugari and Mt. Elgon) were selected. In mid 2007, the Government of Kenya divided Bungoma district into four smaller districts (Bungoma North, East, South and West) and Butere Mumias District into two (Butere and Mumias). However, interventions were maintained in the geographic areas of the original districts. 
To guide the scale up process within Western Province, the DRH and FRONTIERS held stakeholder meetings to create awareness in the four districts in February 2007 through the existing District Health Stakeholders Forum. The communities were represented through the local government administration and members of the health facility boards who are appointed by the community. The DRH and PHMT informed stakeholders about the need for skilled community health services through the community midwife and requested support through the local administration to participate in scaling up the community midwifery approach. Mechanisms for linking self-employed midwives in the community with existing $\mathrm{MOH}$ district level health systems were discussed, as well as potential networks of support (supplies and referral systems) and fee mechanisms that could be utilized to sustain the midwives. At the end of the meetings there was overwhelming support for the community midwifery approach and initial plans made.

The Nursing Council of Kenya, the regulatory body for all nurses and midwives in Kenya, requires private nurse/midwives to pay a fee every year to practice, but the system is fraught with difficulties as the nurses have to travel to Nairobi to get their permits. To implement the community midwifery approach, the NCK was brought on board early in the scale-up process.

For over 20 years, Traditional Birth Attendants (TBAs) have been trained and certified by the Government of Kenya and non government organizations to provide services to women during childbirth at home. They expressed a feeling of betrayal, having been trained for assisting in childbirth and now being disowned. TBA training has been actively discouraged by the $\mathrm{MOH}$ for a number of years, but many TBAs do continue to work in Western Province and they regarded the emergence of the CMs as a rival group. During the stakeholders meeting, the roles and responsibilities of the $\mathrm{CM}$ and other community health workers were discussed.

The DHMTs defined the expected role of the TBA within the community according to Government of Kenya policy. TBAs - trained or not - are excluded from the category of skilled health-care workers. In this context, the term TBA refers to traditional, independent (of the health system), non-formally trained and community-based providers of care during pregnancy, childbirth and the postnatal period (World Health Organization, 2004).

\section{Recruitment and characteristics of Community Midwives}

A skilled birth attendant is an accredited health professional, such as a midwife, doctor or nurse, who has been trained in managing normal (uncomplicated) pregnancies, childbirth and the immediate postnatal period, and in the identification, management and referral of complications in women and newborns (World Health Organization, 2004). For a person to qualify for recruitment as a $\mathrm{CM}$, he or she must meet the following criteria:

- Registered or Enrolled nurse-midwife; or Registered Clinical Officer (with RH experience); or Medical Practitioner.

- Evidence of retention on a professional register (Nursing Council of Kenya (NCK), Kenyan Clinical Officers Council (KCOC), or Medical Practitioners and Dentists Board (MPDB).

- Retired or out of employment.

- Obstetric skills

- Permanent residency within the community to be served, or prepared to live in that community. 
Midwives eligible for selection were identified as follows: the DHMT through the DPHN or District RH Coordinator formally requested the local administration through the chiefs, sub chiefs and village elders to inform any retired or out of work midwives to register their name and attend a one day meeting. All attendees were to bring evidence of their training and work experience. In March 2007, the selected midwives were invited to a one-day meeting in Kakamega Town, the capital of Western Province, during which the MOH and FRONTIERS representatives presented the CM approach in detail. The briefing included selection criteria and outlined aspects that the competency-based training would cover - focused antenatal care, management of labor and childbirth, postnatal care, family planning, counseling in PMTCT, immunizations, birth preparedness and partner involvement. Following discussion and clarification, all sixty midwives expressed interest in participating in the training and dates fixed.

The community midwives were all enrolled community nurses who had been trained in midwifery and family planning in the 1970s. The majority of them retired from public service between 2002 and 2006 (two had never been employed). Only five of the 60 midwives were still practicing as midwives, mostly in single-room clinics situated in the shopping centers or market places. Nevertheless, $58 \mathrm{CMs}$ reported having assisted more than one delivery during the previous three months, and two had assisted a delivery within the previous week. The majority of CMs (56) were women, and three-quarters were aged $55-60$ years. About half of the midwives are now engaged in farming since retirement, 17 percent were operating private clinics on a small scale or providing services from their house. Most CMs (58) were actively involved in church and community activities (e.g. Woman's Guild, church committees, health-related committees and women groups); indeed, when asked why they wanted to become CMs, over half indicated wanting to serve their community.

\section{Development of the community midwifery approach}

A Community Midwifery Task Force ${ }^{2}$ was constituted in 2006 of interested parties from the MOH National Safe Motherhood Working Group. The Task Force was established to develop guidelines and training materials for community midwives and was led by the DRH, with FRONTIERS providing technical and financial support.

The community midwifery guidelines were developed in March 2007and provide an operational manual for implementing the Community Midwifery Approach. The guidelines describe the mandate of community midwives, their responsibilities and involvement in the public health care system at various levels, and the process for implementing this approach. Within the Kenyan context, they also serve to operationalize aspects of the KEPH Level 1 strategy including:

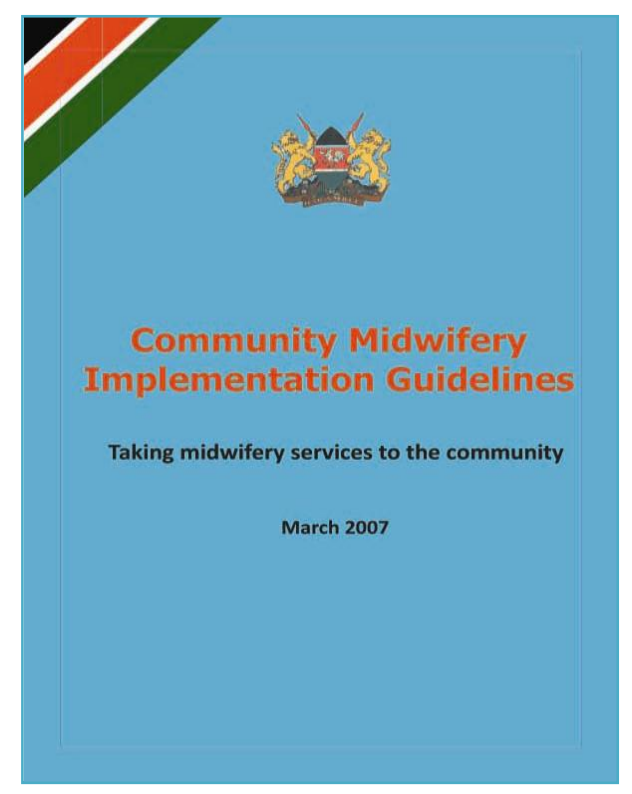

2 Members of the Task Force included: DRH, Population Council, NCK, Dept of Ob/Gyn University of Nairobi, KOGS, NNAK (Midwifery Chapter) DFID, UNFPA, UNICEF, WHO, and FHI. 
i. Providing decentralized services in the community to women and their babies to increase equitable access to professional health care services.

ii. Strengthening linkages between facilities in the health care system and communities through partnership for service delivery.

iii. Strengthening the community to realize their constitutional right to receive professional health care services in a culturally acceptable approach

iv. Build capacity for the community to contribute directly to their health care through cost sharing activities.

During the DFID-funded pilot phase in 2005, CMs had been trained using the 'Essential Obstetric Care Manual for Health Care Providers' (Population Council, MOH and University of Nairobi 2004). However, it was quickly recognized that this manual is focused on providing care within a health facility and not in a woman's home and so it was agreed that a community midwifery orientation package ${ }^{3}$ should be developed that would be more appropriate for the community setting.

A log book was developed for the CMs to record the number of procedures carried out during their competency based training, including details of all aspects of the procedures (ANC, labor, childbirth, and postpartum clinical experience including family planning). New job aids were developed and others adapted to complement these training materials, including:

- Focused Antenatal Care service checklist.

- First postpartum assessment checklist.

- Second postpartum assessment checklist.

- TB screening.

- MOH Combined oral contraceptive screening checklist.

- MOH DMPA screening checklist.

Tools for the CMs and their MOH supervisors were adapted and piloted including:

$\checkmark$ Monthly data and report form.

$\checkmark$ Referral form.

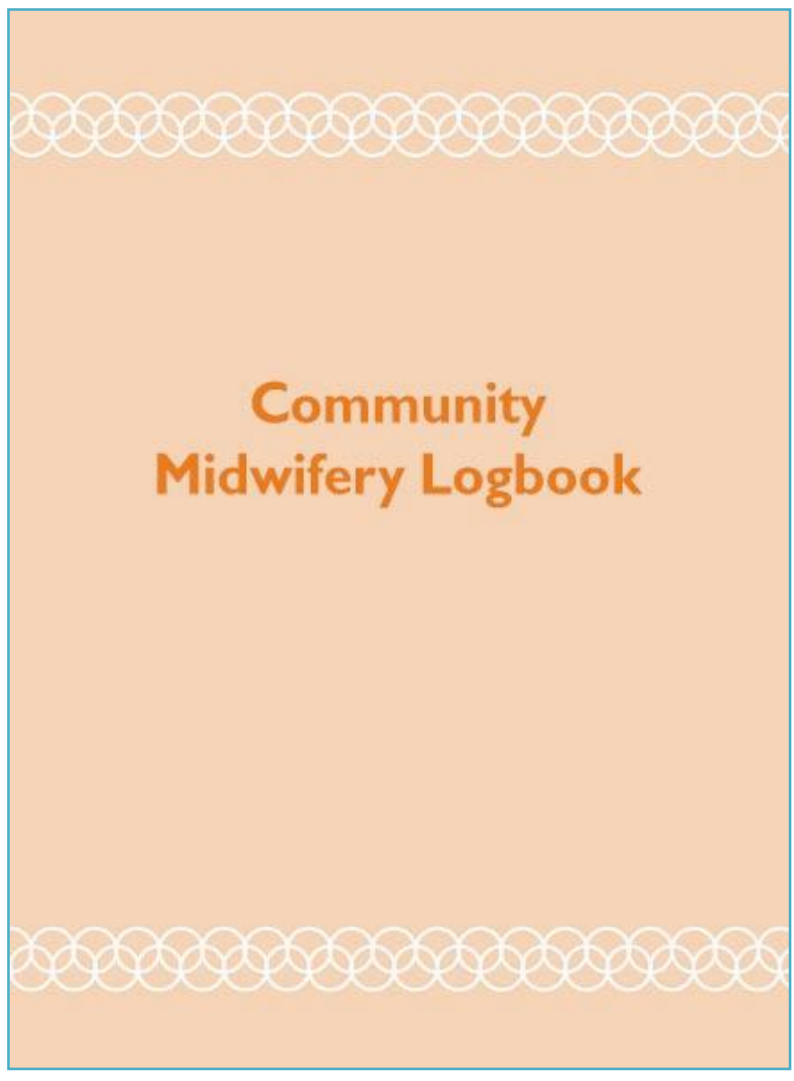

$\checkmark$ Patient summary notes.

3 The concept of an 'Orientation Package' has been used in Kenya for other topics; for example, for Focused ANC (developed by the MOH and Jhpiego) in 2001 and for Targeted Postpartum Care (developed by DRH, Jhpiego and Population Council) in 2007. 


\section{Outline of Community Midwifery Orientation Package}

1. Focused Antenatal Care (including referral for ANC profile, Tetanus Toxoid, birth planning and FP counseling)

2. Management of normal labor and childbirth, and use of the partogram

3. Postnatal care for mother

4. Essential newborn care

5. Family planning and post partum family planning

6. Common complications in the mother and newborn

7. Referral of mother and newborn if complications occur

8. Cross cutting topics

- Infection prevention

- Interpersonal communication and counseling

- Community involvement and participation

- Monitoring and record keeping

Consensus on the content of the package of services that the CMs are allowed and expected to provide was reached by members of the MOH Task Force and other stakeholders. The package consists of the minimum services necessary to ensure that a woman can give birth safely within the confines of her own home, and recognition of complications and initial management of the complications prior to referral (see Table 1). All women are advised to attend a health facility antenatal clinic at least once during pregnancy to receive blood tests, tetanus toxoid (TT) and any prophylaxis. 
Table 1: Mother / baby package of services approved for community midwives

\begin{tabular}{|c|c|c|}
\hline & Mother & Baby \\
\hline $\begin{array}{c}\text { Focused } \\
\text { Antenatal } \\
\text { Care }\end{array}$ & $\begin{array}{ll}\checkmark & \text { Comprehensive history taking } \\
\checkmark & \text { Individual birth planning } \\
\checkmark & \text { Recognition of danger signs in } \\
& \text { pregnancy and referral } \\
\checkmark & \text { IPT for prevention of malaria } \\
\checkmark & \text { Iron supplements to prevent anemia } \\
\checkmark & \text { Tetanus Toxoid vaccination } \\
\text { Counseling on } \\
\checkmark & \text { Prevention of malaria use of ITN } \\
\checkmark & \text { Blood tests (HIV, Hb, Blood group) } \\
\checkmark & \text { Family planning, including postpartum } \\
\checkmark & \text { FP } \\
\checkmark & \text { Care of newborn and infant feeding } \\
\checkmark & \text { Nutrition and hygiene } \\
\checkmark & \text { ARV prophylaxis adherence for those } \\
& \text { women who are positive }\end{array}$ & $\begin{array}{ll}\checkmark & \text { Fetal heart } \\
\checkmark & \text { Fundal height }\end{array}$ \\
\hline $\begin{array}{l}\text { Labor and } \\
\text { childbirth }\end{array}$ & $\begin{array}{l}\checkmark \quad \text { Management of labor using the } \\
\text { partogram } \\
\checkmark \quad \text { Recognition of danger signs during labor } \\
\text { and childbirth and referral } \\
\checkmark \quad \text { Diagnosis of obstructed labor and } \\
\text { management } \\
\checkmark \quad \text { PMTCT: ARV prophylaxis and NVP in } \\
\text { early labor }\end{array}$ & $\begin{array}{ll}\checkmark & \text { Fetal heart } \\
\checkmark & \text { Early recognition of danger signs in } \\
& \text { labor, childbirth and after childbirth } \\
\checkmark & \text { Essential newborn care } \\
\checkmark & \text { Resuscitation }\end{array}$ \\
\hline $\begin{array}{l}\text { Postnatal } \\
\text { period }\end{array}$ & $\begin{array}{ll}\checkmark & \text { First postnatal checkup } \\
\checkmark & \text { Management of postpartum hemorrhage, } \\
& \text { sepsis and pre-eclampsia and eclampsia } \\
\checkmark & \text { Danger signs in the postnatal period } \\
\checkmark & \text { Breastfeeding counseling } \\
\checkmark & \text { LAM and FP counseling and services } \\
\checkmark & \text { Counseling on maternal complications } \\
\checkmark & \text { Counseling on hygiene } \\
\checkmark & \text { Counseling on PMTCT refer for HIV } \\
& \text { services }\end{array}$ & $\begin{array}{ll}\checkmark & \text { Care of the normal newborn, the } \\
& \text { low birth weight and sick newborn } \\
\checkmark & \text { Newborn physical exam, education } \\
\text { on recognition of danger signs } \\
\checkmark & \text { PMTCT: ensure ARV prophylaxis at } \\
& \text { birth and CTX from } 6 \text { weeks } \\
\checkmark & \text { Early initiation and exclusive breast } \\
& \text { feeding } \\
\checkmark & \text { Growth monitoring } \\
\checkmark & \text { Counseling on immunization } \\
\checkmark & \text { Continued counseling on infant } \\
\text { feeding }\end{array}$ \\
\hline \multicolumn{3}{|c|}{$\begin{array}{l}\text { For other services beyond the community midwife's capacity to manage in the home, clients must be } \\
\text { referred to the appropriate institution e.g. } \\
\text { 1. Obstetric complications: high blood pressure ( pre-eclampsia) and eclampsia, severe anemia, } \\
\text { bleeding in pregnancy, severe bleeding after childbirth, obstructed labor/ prolonged labor, } \\
\text { 2. Newborn complications: neonatal asphyxia, prematurity, neonatal sepsis, congenital anomalies, } \\
\text { 3. HIV services: testing, CD4 counts and ART, } \\
\text { 4. long-acting methods of FP, } \\
\text { 5. birth and death registration }\end{array}$} \\
\hline
\end{tabular}




\section{Technical skills training}

Training facilitators, comprising public health nurses, midwives and obstetricians, were drawn from the province, districts and FRONTIERS staff. The training updates were for two weeks and included both theory and practical components. The participants were trained in two groups of 30 participants between April and May 2007.

The community midwives received updates in essential obstetric and newborn care, as well as in family planning and other relevant services. The first week of the training focused on theory using PowerPoint presentations in a classroom setting. Participation was encouraged through the use of plenary and small group discussions, role-play, video shows, games, brainstorming, demonstrations, individual task allocation, case studies, and sharing of personal experiences.

During the second week, all the CMs were expected to undertake clinical practice under supervision at busy maternity units and MCH-FP clinics for a minimum of 5 days. The CMs were observed performing specified procedures to improve skills and competency. All CMs were expected to do the following:

a) Give health talks;

b) Provide Focused ANC;

c) Assist ten births;

d) Understand and use the partogram;

e) Manual removal of the placenta;

f) Vaginal examination;

g) Perform and repair episiotomies;

h) Manage maternal and newborn complications, such as pre-eclampsia, ante partum and post partum hemorrhage, neonatal asphyxia, low birth weight etc

i) Postpartum family planning counseling and provision of oral contraceptives, condoms and injectables. Referral for methods such as IUD, implants, tubal ligation and vasectomy.

To be certified, each community midwife had to be observed assisting ten women during childbirth in a health facility and performing the first postnatal examination for mother and baby under the supervision of a senior midwife on the ward. Each CM was given a log book to record all completed procedures; the senior midwife then signed the log book for all satisfactorily performed procedures. The District RH Coordinator, who is also the District Public Health Nurse, then visits the facility regularly to assess the CM's performance. Of the 60 midwives recruited, $51(85 \%)$ managed to complete the training within the planned period of two weeks and the remainder successfully completed all the procedures during a third week of training. On successful completion of the certification process the CM is issued a certificate from the Ministry of Health, jointly signed by the Head of the Division of Reproductive Health and the Kenya Nursing Council Registrar. 


\section{Basic delivery kit}

In response to the need for basic commodities and supplies to help the CMs start in their new role, the $\mathrm{MOH}$ (with funding from this project) provided each $\mathrm{CM}$ with a basic delivery kit (Table 2). The contents of this kit were agreed upon after wide consultation with members of the Safe Motherhood group of the DRH. The non-disposable items of the kit remain the property of the $\mathrm{MOH}$ and are registered in the inventory of the nearest public health facility to the community midwife.

\section{Table 2: Childbirth kit and basic supplies}

\begin{tabular}{|c|c|}
\hline $\begin{array}{l}\text { - Pair of episiotomy scissors } \\
\text { - Needle holder } \\
\text { - Toothed dissecting forceps } \\
\text { - Small gallipots 8-10 cm diameter (2) } \\
\text { - Mucus extractor } \\
\text { - Foetoscope } \\
\text { - Blood pressure machine } \\
\text { - Baby weighing scale } \\
\text { - Stethoscope } \\
\text { - Mackintosh (one meter square) } \\
\text { - Holdall }\end{array}$ & 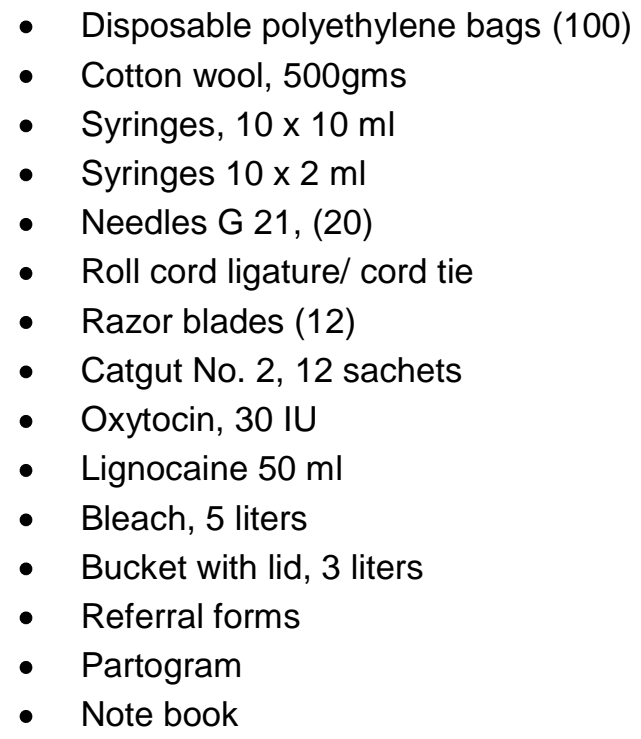 \\
\hline
\end{tabular}

The Ministry of Health, through the District Public Health Nurse, provides the CMs with basic RH commodities such as oral and injectable contraceptives, condoms, gloves, needles and syringes; supplies were occasionally hampered by commodity stock-outs, however. To receive new stocks of supplies, the CM is expected to forward a report every month showing the utilization and anticipated need for more commodities. The DPHN will then supply the commodities requested. When commodities are not available in the district stores, some CMs purchase the commodity privately and then provide it at cost to the clients.

\section{Linkages, support and networking}

A one-day meeting, between the CMs, the Nursing Officers in charge of the selected health facilities, the local government administration, and the PHMT and DHMTs served as the foundation for a strong collaboration and linkage between the community and the formal health care system. Each CM is attached to the nearest public health facility in the community. For the CMs to deliver quality health care services mechanisms for supportive supervision and monitoring must exist within the health care system; such links are also necessary for the CMs to access continuing education, commodities and supplies, such as contraceptives and gloves. To enhance this linkage, the DHMT assigned the District Public Health Nurse (DPHN), who is also 
the Reproductive Health Coordinator in each district, to supervise the CMs and to monitor their activities in the community. All reports from the CMs on services provided in the community reach the health care system from the facility and then through the DPHN.

The local government administration's role (i.e. chiefs and sub-chiefs) is to create awareness about health seeking behavior in support of the government policies. The CM is able to use the local administration forum to inform, educate and communicate health concerns in her community. Security in communities at night can be a challenge, and in many cases the chief organizes a security team to escort the midwife to the women's' houses.

One component of the approach that has contributed to its success is the development of ' $\mathrm{CM}$ clusters' or networks within the districts. Groups of CMs were encouraged to form their own 'associations' to provide peer support and a forum to discuss management of clients. All CMs are also encouraged to be members of the private nurse/midwives chapter of the National Nurses Association of Kenya.

\section{Cost and payment for services prior to scale up}

Financial and logistical support is central to continuation of the CMs' activities. During the pilot phase in 2005, CMs were receiving inadequate financial compensation from their clients. As a result, the initial CMs were not able to live on the income from providing these services. Although extensive discussions took place between community leaders, community members, potential users and the CMs on the importance of payment for services, most clients appeared too poor to pay, even though no other health services were available. Some agreements were reached between community members and their CMs concerning the modality of payment for their services, which included payment in installments or 'in kind' rather than in cash; "in kind' payments included farm produce or free labor from the woman or her husband. When the midwife had worked closely with the local administration she had better financial support from the community because they made efforts to advocate for payment for services.

It soon became apparent that some training in basic business skills was critical if the CM approach was to be sustainable. To sustain their services, it was estimated that the charge for a total package of ANC, childbirth and PNC should be at least \$23 per client. Another solution for improving sustainability was facilitating the clusters of CMs to pool their resources through a 'Merry-Go-Round", thereby enabling them to buy supplies in bulk or to purchase equipment that can be shared. A Merry-Go-Round is an income-generation and resource-mobilization activity whereby members in a group contribute to a common kitty at specific intervals. The group contribution is then distributed to members in turns until all members have had a share. CM groups have also linked themselves to local microfinance enterprises (such as the Lugar District midwives) and benefited from the continuous motivation received from the microfinance field offices.

\section{Business skills training}

On average, the CMs were charging approximately US\$7 for assisting in childbirth, which was well below the cost of materials used and did not reflect the time spent. Other services such as ANC, PNC and newborn care services were being offered free. Community-wide poverty was 
cited as the main reason for low or non-payment of fees and failure to pay debts. As the CMs did not have any business skills, they lacked the capacity to view their services as a business opportunity that could be used to sustain their livelihood. To address this need, the DRH and FRONTIERS contracted a Kenyan NGO specialized in community-level business training, Mwangaza Business Development Services (MBDS), to develop a short training module and to conduct business management skills training for the CMs. The training was expected to equip the midwives with knowledge and skills to be able to provide midwifery and other services as a business. The training was expected to:

1. Equip the trainees with entrepreneurship skills and relevant concepts to manage a successful community midwifery business, including setting realistic prices for the services provided and identifying strategies for getting paid for the services provided;

2. Sensitize the trainees with (practical) application of the entrepreneurship and relevant skills and strategies to develop or initiate successful business.

To achieve these objectives, a training workbook on business skills for beginners was adapted and used by the consultant as a training document in a group training workshop. The workbook has five modules (see Table 3 ) and was designed to be used in a participatory manner to help trainees review the business ideas, with the aim of equipping them with the relevant business management skills. The focus of the two and half day workshop was for CMs to share the financial challenges they faced in providing services in the community and to help each other come up with ideas on how to overcome these challenges. The MBDS facilitated the whole process and was able to encourage the CMs to think 'out of the box' regarding themselves and the way they work. The CMs felt that this was important for their professional development and recommended it for other health care providers in the health system (See Annex 2 for a sample business plan.

Table 3: Content of the Community Midwifery business skills training

\begin{tabular}{|c|c|}
\hline Module & Content \\
\hline Introduction to entrepreneurship & $\begin{array}{l}\text { - } \text { Personal experience in business } \\
\text { - } \quad \text { Characteristics of a good and bad entrepreneur } \\
\text { - Self assessment as an entrepreneur }\end{array}$ \\
\hline Marketing & $\begin{array}{ll}\text { - } & \text { Knowing your customers } \\
\text { - } & \text { Knowing your competitors } \\
\text { - } & \text { Location of the business }\end{array}$ \\
\hline Organization & $\begin{array}{ll}\text { - } & \text { Cost of business } \\
\text { - } & \text { Control of quality } \\
\text { - } & \text { Control of debtors }\end{array}$ \\
\hline Financing & $\begin{array}{ll} & \text { Cost of materials } \\
\text { - } & \text { Projection of income } \\
\text { - } & \text { Keeping a cash record } \\
\end{array}$ \\
\hline Planning & - Making a business implementation plan \\
\hline
\end{tabular}


An assessment of the CM activities five months after the business skills training was undertaken showed that all CMs were now sustaining their services. Virtually all (96\%) of CMs reported a positive change in their business, 88 percent indicated that they had increased the number of customers, and over one quarter reported having hired an assistant. To cut on costs, 65 percent indicated that they had started buying wholesale those commodities that were out of stock in the health care system, while 90 percent reported improved debt collection from the community.

\section{Transport and referral}

Transportation mechanisms were identified within the communities to strengthen referrals for clients to health facilities, particularly during emergencies. Community members identified existing vehicles within the community that could be easily accessed during emergencies and developed their own plans for making them available, such as bicycles (with or without a trailer), donkey carts, private vehicles and ambulances. Where health facilities already have access to a vehicle to be used for emergencies or onward referrals, it is important to have an emergency fuel fund available. Telephone contacts for the officers responsible for transport at the facility were given to all the CMs referring patients to the facility.

In Bungoma and Butere Mumias districts, bicycle-pulled trailers were introduced by FRONTIERS. Five bicycle-trailers were constructed; the bicycle and their trailer remain the property of the DHMT but were assigned to the CMs for their use during referrals and emergencies. The District RH Coordinator and the community leader are jointly responsible for monitoring their utilization on behalf of the DHMT and the community. Community members make arrangements for the person who will pedal the bicycle and take responsibility for maintenance and repairs. To date, however, their utilization has been minimal. Although use of bicycles is very common in this province, there is no documented evidence of these bicycletrailers being used for transporting either clients or commodities; the reasons why they have not been used need to be understood.

\section{Monitoring and supervision}

The DRH, with support from FRONTIERS, developed recordkeeping tools (see Annex 3) to track the use of CM services at the district level; these data are now absorbed into the $\mathrm{MOH}$ HMIS to determine whether or not the proportion of women having skilled attendants increases. The CMs were given standardized reporting forms on which they reported the number of referrals made for ANC, IMCI, EPI, long-acting FP methods, PNC as well as referrals for emergency care, deliveries attended, and family planning counseling consultations held. These forms are handed to the head of the nearest health facility on a monthly basis in return for basic consumable supplies. The reports are subsequently sent to the DPHN and incorporated into the regular district report. The cluster of $\mathrm{CMs}$ in each district meets periodically to discuss their work and provide peer support; where possible, the DPHN also attends these meetings. In addition, staff from FRONTIERS and the DHMTS made occasional supervisory visits to individual CMs during the project period. 


\section{Legitimatizing community midwifery within the Kenya MOH}

Midwifery and nursing practice in Kenya is licensed by the Nursing Council of Kenya. However, for a nurse midwife to practice privately a license issued by the Director of Health Services is required. The process of obtaining a license is expensive and can take years. Through lobbying and negotiations with the Nursing Council and the DRH, an agreement was reached in 2005 that a CM will receive a certificate to practice after completing the training/orientation package, which is signed by the Registrar of the Nursing Council and the Head of the DRH. The certificate permits the CM to provide services at the client's house only. If the midwife also runs a private clinic she must have a license to practice from the Director of Medical Services which is renewed annually. The certificate provides a means of legitimizing the community midwifery approach through endorsement by the DRH and the NCK, thereby harmonizing the relationship between the community midwives and the health care system. The CMs are seen as complementary to the $\mathrm{MOH}$ services.

\section{EVALUATION}

\section{Methodology}

An assessment was planned at the end of the six-month implementation period to document the extent to which activities to sustain and replicate the model had been successfully introduced and to allow a judgment to be made concerning whether to recommend the approach for wider scaling up and replication. However, due to the political instability and post-election violence experienced in Kenya from December 2007 to February 2008, the individual face-to-face interviews and focus group discussions planned with the CMs and their clients could not be undertaken ${ }^{4}$.

Consequently, telephone interviews were used instead. Community midwives were informed several days in advance about the format of the interview and a mutually convenient time agreed before the interviews were carried out. Thirty of the 59 community midwives were interviewed. At the end of each interview, the CMs were asked to provide names of five clients they had attended in the preceding six months, out of which one was randomly selected for the client interview; fifteen clients were interviewed altogether. The client was contacted well in advance of the interview; if she did not have a phone then the $\mathrm{CM}$ was requested provide the information and her cell phone during the interview. The client consented before being interviewed on the day of the interview. Client interviews were used to ascertain their perceptions of barriers and operational challenges that may influence their acceptance of home deliveries and postnatal visits, and the providers' attitudes towards the changes in policy and procedures needed to provide the new package of care. A recording gadget with software that also streams audio data to a computer was installed; once the audio interviews were recorded on a file on the computer, they were played back, transcribed and then analyzed. The analysis was done by collating, summarizing and drawing themes from the data collected, both from the CMs and their clients.

$4 \quad$ The findings describing the results from the business skills evaluation were collected from the CMs during their follow up business skills workshop in November 2007. 
The mean age of the clients was 27 years, ranging from 18 to 35 years, and most (13/15) were married. Eight of them had 4-6 children, three had 2-3 children, and four had one child. Eight clients finished primary school, three did not complete primary school, and five attended 10-12 years of schooling.

\section{Findings}

Assistance during childbirth: The 19 CMs recruited during the pilot study (2005) contributed to three percent of all births assisted by a skilled attendant in 2006 in the four districts. Following the addition of the 60 new CMs in the four districts in the second half of 2007, this proportion increased to six percent for the year in the four districts. Only 13 percent of all births in these four districts were attended by a skilled attendant (see Table 4). This is well below the national average of 42 percent. There is still a long way to go in increasing skilled attendance generally and indicates the urgent need to find alternative ways to increase this proportion.

Table 4: Skilled attendants during childbirth in the districts in 2007

\begin{tabular}{|l|c|c|c|c|c|c|c|c|}
\hline District & $\begin{array}{c}\text { Expected } \\
\text { live births }\end{array}$ & \multicolumn{2}{|c|}{$\begin{array}{c}\text { Deliveries by } \\
\text { skilled attendant }\end{array}$} & \multicolumn{2}{|c|}{$\begin{array}{c}\text { Deliveries at } \\
\text { facility }\end{array}$} & \multicolumn{2}{|c|}{$\begin{array}{c}\text { Deliveries } \\
\text { by CM }\end{array}$} & $\begin{array}{c}\text { \% skilled } \\
\text { deliveries by } \\
\text { CM }\end{array}$ \\
\hline Lugari & 12,696 & 2047 & $16.1 \%$ & 1,829 & $14.4 \%$ & 218 & $1.7 \%$ & $10.6 \%$ \\
\hline Mt Elgon & 9,340 & 970 & $10.4 \%$ & 749 & $8.0 \%$ & 221 & $2.4 \%$ & $22.8 \%$ \\
\hline Bungoma & 58,110 & 7453 & $13.0 \%$ & 7199 & $12.4 \%$ & 254 & $0.6 \%$ & $3.4 \%$ \\
\hline Butere Mumias & 28,920 & 3880 & $13.4 \%$ & 3684 & $12.7 \%$ & 196 & $0.7 \%$ & $5.1 \%$ \\
\hline Total & $\mathbf{1 0 9 , 0 6 6}$ & $\mathbf{1 4 3 5 0}$ & $\mathbf{1 3 . 2 \%}$ & $\mathbf{1 3 , 4 6 1}$ & $\mathbf{1 2 . 3} \%$ & $\mathbf{8 8 9}$ & $\mathbf{1 . 0 \%}$ & $\mathbf{6 . 1 \%}$ \\
\hline
\end{tabular}

The CM approach has been particularly effective in Mt. Elgon district, which is a remote rural district with limited infrastructure that borders Uganda. There are only 13 public health facilities (one hospital, three health centers and nine dispensaries); the 'district hospital' was previously a health center and there is only doctor, who is the District Medical Officer. The district is dominated by a mountain and there has been armed conflict recently due to land disputes, both of which reduce peoples' freedom to move around and to access health care from facilities. In addition none of the health facilities are connected to an electricity supply.

The $17 \mathrm{CMs}$ in Mt. Elgon district have contributed to increasing the proportion of skilled attendance at childbirth, both by increasing the number of births delivered in facilities through referrals, as well by providing assisted deliveries at home. In 2003, the skilled attendance rate in Mt. Elgon was 3.7 percent; by 2005 this rate had increased to 6 percent and by the end of 2007 it was 10.4 percent, of which almost one quarter were deliveries attended by CMs. Table 5 shows the contribution of CMs towards professionally attended deliveries since 2005 in the four districts $^{5}$.

$5 \quad$ It should be noted that the geographic areas and district populations vary considerably and so the numbers per district cannot be compared. 
Table 5: Number of births delivered by skilled attendants by type of attendant

\begin{tabular}{|c|c|c|c|c|}
\hline District & Skilled attendant & $\mathbf{2 0 0 5}$ & $\mathbf{2 0 0 6}$ & $\mathbf{2 0 0 7}$ \\
\hline \multirow{2}{*}{ Mt. Elgon } & $\mathrm{CM}$ & 15 & 129 & 221 \\
\cline { 2 - 5 } & Facility & 549 & 653 & 749 \\
\hline \multirow{2}{*}{ Lugari } & $\mathrm{CM}$ & 10 & 94 & 218 \\
\cline { 2 - 5 } & Facility & Not available & 1,067 & 1,829 \\
\hline \multirow{2}{*}{ Bungoma } & $\mathrm{CM}$ & 12 & 83 & 254 \\
\cline { 2 - 5 } & Facility & Not available & 9,276 & 7,199 \\
\hline \multirow{2}{*}{$\begin{array}{c}\text { Butere } \\
\text { Mumias }\end{array}$} & $\mathrm{CM}$ & 32 & 147 & 196 \\
\cline { 2 - 5 } & Facility & 712 & 3,288 & 3,684 \\
\hline
\end{tabular}

Postnatal care: All women assisted by the CMs during birth are expected to receive the first postnatal assessment with their babies within six hours of delivery and a second assessment within the first three days of childbirth. All 889 mothers and their babies received the first postnatal assessment, and 117 of these received a second assessment from the CMs.

Immunization coverage and birth registration: All women assisted during childbirth by the CMs are expected to be referred to the area chief for birth notification and to nearest health facility for immunization. It was not easy to get the actual numbers of mothers who were referred and received the birth notification and immunization and so the effectiveness of this intervention is not known.

Identification of complications and referrals: Table 6 describes the obstetric and medical conditions for the 61 women that the CMs referred to health facilities for further management. Twelve clients (14\%) were among the 889 women delivered by the CMs, of which seven were referred due to postpartum hemorrhage, three due to retained placenta, and two for babies with spina bifida and prematurity. The majority of referrals were for obstructed labor, malaria or anemia during pregnancy and postpartum hemorrhage. As noted by a CM in Lugari:

"Referral of clients has become easy. Once I recognize a danger sign I fill the referral form we were given by the DPHN. If necessary, I accompany the client but if there is no cause for alarm I encourage the relatives to escort her to hospital. As long as the referral sheet indicating the reason for referral is filled, the client receives immediate attention. This was not the case a year ago." CM, Lugari 
Table 6: Number of women referred by community midwives and reasons for referral

\begin{tabular}{|l|c|c|}
\hline Reason for referral & Number referred & $\begin{array}{c}\text { Total referrals } \\
\%\end{array}$ \\
\hline Obstructed labor & 12 & $20 \%$ \\
\hline Malaria in Pregnancy & 10 & $16 \%$ \\
\hline Anemia in pregnancy & 8 & $13 \%$ \\
\hline Postpartum hemorrhage & 7 & $12 \%$ \\
\hline Retained placenta & 3 & $5 \%$ \\
\hline Fetal distress & 4 & $7 \%$ \\
\hline Previous surgical birth & 4 & $7 \%$ \\
\hline Sepsis & 4 & $7 \%$ \\
\hline Severe PET & 3 & $5 \%$ \\
\hline Multiple pregnancy & 3 & $5 \%$ \\
\hline Ruptured uterus & 1 & $1 \%$ \\
\hline Baby with spina bifida & 1 & $1 \%$ \\
\hline Prematurity & 1 & $1 \%$ \\
\hline Total & 61 & $100 \%$ \\
\hline
\end{tabular}

Family planning: Community midwives were trained and encouraged to discuss FP with their pregnant and postpartum clients. All midwives were conversant with almost all family planning methods from their pre-service training, clinical experience and continuous professional development during in service. About half of the CMs had been trained in family planning through in-service training ${ }^{7}$ and could counsel and provide all methods except permanent and long-term methods; the CMs are expected to refer clients to the health facilities for these methods. The CM is also expected to advise postpartum women to go for the six week check up and on the importance of postpartum family planning.

Very few clients approve of couple counseling. Many women indicated that they want to use FP, but their partners do not necessarily agree to them using modern methods. However some CMs are able to meet their clients' needs, as one woman put it:

'My husband is not for FP and persistently refused for me to use FP. I am a mother of six, all under the age of 15 years. I discussed the situation with the community midwife who happens to be my neighbor. Through her services I am now on the Depo injection and my husband has no clue".

\footnotetext{
$6 \quad$ The only ruptured uterus was associated with a herbal treatment given to augment labor by the woman's relatives and the TBA before seeking professional care.

7 The MOH FP course that most CMs attended used to run for a minimum of six weeks.
} 
Prior to the scale up and recruitment of the new CMs in 2007, none were providing, nor were they mandated to provide, FP methods in the community, However the Head of DRH stipulated during the national dissemination meeting in April 2008 that the DPHNs are expected to supply FP commodities to the CMs. However, stock-outs of commodities in the district stores affect supplies to the CMs as well as to the MOH facilities. Nevertheless, when this does occur, the CMs usually procure the FP commodities themselves and sell them to their clients at a slight profit to cover their costs; for example, Depo provera is purchased at US\$0.50 and sold to clients at US\$0.70. The majority of clients receiving FP services from the CMs are women who also received care during pregnancy and childbirth from them.

Although the CMs do not themselves provide long-acting and permanent FP methods, three women were referred for tubal ligation in the second half of 2007. No reports were received for referrals for implants or IUD. However, CMs reports on provision of FP methods is now incorporated into the provincial data collection system and submitted to the national department.

As can be seen in Table 7, CMs are now contributing significantly to the provision of FP commodities, especially in Lugari District. Why this should be so is unclear, but the population includes people moving into the area and so women may possibly be more open to using FP than those in other districts. Moreover, the GTZ-supported CBD program was previously active in Lugari district, which may also explain both the higher levels of FP use and also the acceptability of providing FP methods through community-level providers. Conversely, Mt Elgon district is very conservative; indeed, during a previous evaluation of cultural issues affecting access to maternal and newborn health services, interviewers were told to stop talking about 'those things' (Rumbold and Warren 2005).

Table 7: Proportion of FP commodities in a district delivered by Community Midwives in 2007

\begin{tabular}{|l|c|c|c|}
\hline District & Injectables (\%) & Pills (\%) & Condoms (\%) \\
\hline Lugari & 11 & 19 & 1 \\
\hline Mt Elgon & 3 & 2 & 1 \\
\hline Bungoma & 2 & 1 & 1 \\
\hline Butere-Mumias & 1 & 6 & 20 \\
\hline
\end{tabular}

\section{Financial sustainability of the community midwifery approach}

Following the business skills training, 88 percent of the CMs increased both their revenue and the number of clients served. Prior to July 2007, out of the $60 \mathrm{CM}$, six were providing the package of services for pregnancy, labor and childbirth, and postnatal care for free, 41 charged between $\$ 5$ and $\$ 14$ for the package, and two charged about $\$ 40$. The minimum cost of supplies used for these services was calculated to be $\$ 15$. Most CMs were not even covering these costs and so were not generating any income. 
After the business training it was clear that the revenue collected was adequate to sustain the services and generate an income for the midwives; most CMs were able to recover the cost of supplies and to gain some profit to cover their time, with the average profit margin for providing the whole package of care (ANC, delivery and PNC) being around $\$ 5$ per client.

Table 8: Comparison between service charges by CMs and at MOH facilities

\begin{tabular}{|l|c|c|l|c|c|}
\hline \multicolumn{3}{|c|}{ Maternal and newborn care } & \multicolumn{3}{c|}{ Family planning } \\
\hline & CM & Facility & & CM & Facility \\
\hline First ANC consultation & $\$ 1.55$ & $\$ 1.96$ & Injectable & $\$ 0.77$ & $\$$ free \\
\hline Subsequent ANC consultations & $\$ 0.30$ & $\$ 0.66$ & Cycles of pills & $\$$ Free & $\$$ free \\
\hline Childbirth & $\$ 15.40$ & $\$ 5.21$ & Condoms & $\$$ Free & $\$$ free \\
\hline Postnatal & $\$ 1.55$ & $\$ 0.66$ & Counseling & $\$$ & $\$$ \\
\hline
\end{tabular}

Moreover, 22 percent of the CMs had hired an assistant, 90 percent reported improved debt collection and over 80 percent had initiated financial/book recording keeping. The CMs reported developing innovative ways of receiving reimbursement, compensation and profit for their services, for example:

- Exchange of services with farm produce: Many people in Western Province produce cereals, sweet potatoes and groundnuts and some CMs accepted payment "in kind" from women who could not pay in cash. One of the CMs from Mt. Elgon reported that she had opened a cereal store through this arrangement.

- Exchange of services for labor: One CM agreed with the woman's husband to accept him digging a piece of her land as payment.

- Exchange of services for rent-free land: Another CM received a piece of land from a client's husband to use as compensation for her services. She planted onions on the plot and at the end of the season sold the onions, which fetched ten times the cost of the services.

- Payment of services by installments: Clients are often allowed to pay in installments over an agreed period of time, which appears to work well in most cases.

- $\quad$ Purchasing commodities not supplied by the MOH though wholesale: The community midwives recognized the benefits of purchasing their supplies in large quantities through wholesale to improve on the profit margin; for example, a tin of 1,000 tablets of iron costs about $\$ 1.5$ and if sold individually to clients can make $\$ 3$. The clients were more comfortable with this arrangement as it reduced the cost and time for seeking the same services in the health care system and the risks of not receiving them due to the regular stock outs.

- $\quad$ FP services are more rewarding Although the community midwives were initially trained to increase the proportion of women assisted by skilled attendants during birth, the majority of CMs indicated that provision of FP methods enabled them to make a higher profit. 
One midwife said that:

"We are now able to budget for what to buy and keep proper records of income and expenditure accounts. This helps keep track of the stock and to gauge how the business is performing. We have also extended this knowledge to our clients. We advise expectant mothers to prepare for the birth of their babies by setting some amount of money aside to cater for delivery expenses. This comes as a blessing to the community midwives, as the mothers are then able to pay for services rendered by the community midwives." (CM in Lugari).

\section{Clients' views of community midwifery}

Community midwifery has fostered a healthy relationship between the community and the health care system. Clients are able to contact CMs easily, either by calling on their mobile phones, walking to their residence or sending members of the family whenever they need services. Clients appear to be well aware of the range of services provided by community midwives. Clients like the personalized care they receive from the CM as many women find the health facilities unfriendly.

"The community midwife [the client actually referred to her as 'doctor'] is a big blessing to us women. We no longer have to visit the hospital and spend a whole day being tossed up and down by the rude 'sisters' [referring to nurses]".

Clients felt that staff in the health facilities do not provide as thorough care as the CMs and dislike the long waiting times, usually over three hours, as well as having to travel to the health facility and back home: "Some of the investigations were not done and I regret having wasted my day." Other clients want skilled care but do not attend the facility as they do not like to be attended by "...young nurses and doctors who are their children's age ..."

Clients mentioned liking being able to receive the CM services at their homes and thought that

CMs were fair in the amount they charge for the amount of work they do for the clients. If women go into labor at night, the CM usually stays with them until morning and after delivery will make sure the client and her baby are clean and comfortable before leaving. Moreover, the CMs do not "harass and abuse clients like some other health workers".

"I delivered my first born in hospital because I was afraid of delivering at home. It was my first pregnancy. If you get problems when you deliver at home, no one can help you, but if you get problems in hospital, they can help you. For the second child, I delivered at home because I was already experienced and I had no fear, like the first time. It was also at night. For the third child, I delivered at home since I had gone to visit my parent's home. It was also at night and the TBA was nearer. I preferred going to the TBA because she was nearer to me compared to the hospital. For the fourth child, I delivered with the community midwife because she was nearer to me and I was alone in the house. I chose her because I knew her, even when she used to work at the health center before". Client 


\section{DISCUSSION}

The community midwifery intervention was developed as a response to the need for expanding legitimate skilled care in pregnancy, delivery, postnatal care and family planning at the community level. The community midwifery approach in Kenya has demonstrated that retired / non-employed qualified midwives can be trained to offer effective and quality maternal, newborn and family planning services at the community level on a self-employed basis and working in close partnership with the public health system. The Ministry of Health in Kenya, as in most African countries, is exploring ways of working more closely with communities through formal and informal arrangements and alliances, as well as extending the range of publicprivate partnerships that enable alternative funding mechanisms to be used for essential health care.

Evidence of the effectiveness of this approach from the DFID-funded pilot project was reinforced by the experiences with this project in demonstrating the ability of community midwives to provide safe and appropriate care during pregnancy, to attend deliveries, to provide postnatal care, to refer complications, and to both deliver and refer for family planning. Introducing the CM approach appears to have increased the proportion of births with skilled attendance in all the project districts and therefore is an important and effective strategy for helping Kenya (and possibly other countries) to achieve the maternal health MDG. Training CMs to counsel clients on family planning and provide or refer for contraceptive methods has impacted on how women obtain their methods, as well as increasing the number of FP commodities delivered in the districts. Although the proportions are on the lower side the $\mathrm{MOH}$ is now committed to ensuring FP commodities are made available to all CMs as stated in the national dissemination meeting in April 2008. DPHNs have separate stock to the health facilities specifically for distribution to CMs.

Training the CMs in basic business skills was an important innovation of this project. It is probably the key factor in increasing the likelihood of the CMs becoming financially selfsustaining. As was seen in the initial pilot phase in 2005, and by other development partners that have funded training of CMs in other districts, there is inevitably an attrition of some the CMs, especially those that have not been trained in business skills or were not provided with the basic delivery kit and a start-up supply of commodities. One way to strengthen the business component of the model is for DHMTs to liaise with existing microfinance enterprises that operate in rural areas, such as K-Rep, Kenya Women's Financial Trust (KWFT), Faulu, SMEP and Equity Bank. All of these institutions have field officers who could train and provide support for clusters of CMs to develop business skills.

One major challenge for CMs working in these remote areas is that many women have very limited funds to pay for the services and are not covered by the health insurance scheme. If women are unable to meet the costs then the community midwives are unable to replenish their supplies or continue to be motivated to provide the services. Although the situation has improved after training in business skills, it was felt that, as a business, this model could not be sustained in the long term without a subsidy or reimbursement of the cost of providing the services from another source. 
Currently, maternal health services are supposed to be provided for free within public health facilities. Women may pay for ANC services from the community midwife but then go to the dispensary or health center for delivery, where the $\mathrm{MOH}$ provides the service free. But traveling to a facility incurs travel expenses and so women may be delivered by relatives in their houses and the CMs are called upon when a complication occurs.

To effectively sustain this service within the public health system, the $\mathrm{MOH}$ needs to reimburse the CMs for services rendered, as well as ensure the regular supply of commodities through the DHMT. The MOH's Community Strategy (2006) includes a cadre called 'Community Extension Workers' (CEWs) that are expected to provide services in the community. These CEWs are expected to be enrolled nurses and public health technicians and to be paid a salary by the $\mathrm{MOH}$, and so there is no reason why the CMs could not be included within the cadre of CEWs.

Based on the lessons learned from the pilot project and this study, the roles and responsibilities of the CMs have now been clearly articulated in $\mathrm{MOH}$ guidelines and training materials specifically for CMs; these materials enhance the possibility of institutionalizing the model within the national policy and program. The roles, responsibilities and authorization of health providers at other levels of care need to be made clearer, however, in order to realize the full potential of the CMs. Although the guidelines are clear, this information needs to be articulated at all levels of the health care system. The involvement of other relevant government departments, such as gender and social services, is also critical. The support provided to CMs is undermined by the confusion that currently exists over the limits of the activities that a community midwife can undertake (Rumbold 2006). A clearer organizational structure, with well-defined roles and responsibilities of all actors at all levels, is necessary to ensure the success of community service delivery.

Many women and their families have expressed a demand for additional services from the CM that are beyond what is currently mandated. Some of these services could feasibly be provided by the CMs including: testing for HIV and provision of ARVs for PMTCT; treatment of minor illnesses, particularly in infants and young children; and provision of long-acting methods of FP. Whether and how to expand the mandate of the CM model without compromising safety and the quality of care is a challenge that needs to be addressed through further operations research to strengthen the contribution this approach can make in the areas of family planning and HIV.

Introduction and scaling up of the community midwifery approach in Western Province has demonstrated the potential for introducing and rolling out the approach in other provinces of Kenya, as well as in other countries with similarly high levels of under-utilized qualified and experienced midwives. Acceptability within the community is high because the midwives come from them same cultural background and can understand their cultural beliefs and practices, socio-economic status and language, while the $\mathrm{MOH}$ supports their professional skills and values their contribution to increasing access to safe delivery and family planning services. 


\section{RECOMMENDATIONS}

1. Support skills development for maintenance of quality of care: Professional bodies such as the nursing council, the professional associations and the Ministry of Health need to establish systems for ensuring continued professional competency for quality health care in the community. This could include specified hours for continuous professional development per year, theory and clinical practice included.

2. Support the community midwives to achieve financial sustainability: For this model to continue within the public health system, a monthly stipend would enable midwives to replenish supplies and allow them to offer services to low-income clients who could not pay the full service fees. Alternatively, it would be important to explore ways of developing alternative health financing models that could support this model, such as the Output Based Aid (OBA) approach currently being pilot-tested by the Kenyan Government, or a social franchising model as is being undertaken with private midwives in other countries.

3. Strengthen the business skills: all CMs must be provided with basic business skills to build their capacity in running the services, regardless of the health financing model through which they are supported. In addition, DHMTs should link with local offices of microfinance enterprises to support the CMs' networks in developing their business skills and savings.

4. Strengthen and support the linkages between the $\mathrm{CM}$ and the formal health sector through the DHMT: The CM is a potentially important source of information about health status and services at the community level for the health care system. To achieve this, appropriate tools for data collection in the community are important and the $\mathrm{MOH}$ would benefit tremendously by developing and providing such tools to collect these data.

\section{DISSEMINATION AND UTILIZATION OF FINDINGS}

The MOH launched the CM approach through a speech by the Assistant Minister in Western Province in October 2006, and distributed the CM Guidelines in mid-2007. The preliminary findings and lessons learned from this project were communicated to key stakeholders in April 2008. Following the findings of the DFID-supported pilot project, a number of development partners had already supported training of CMs in other parts of the country; to date, four UNFPA-supported districts (Nyandarua in Central Province, Mwingi in Eastern Province and Kilifi and Taita Taveta districts in Coast Province) have trained over $70 \mathrm{CMs}$ in the last 18 months. With technical assistance from FRONTIERS, Maragua district in Central Province trained 27 midwives in March 2008. The USAID-funded APHIA II project in Coast Province trained 40 community midwives from Lamu, Malindi, Kwale and Kilifi districts and the APHIA II project in Rift Valley province has trained twelve midwives from Kajiado and Loitokok districts, with further training planned for August 2008. The DFID-funded 'Essential Health Services' project is about to train 40 midwives in two districts in Nyanza Province. Lessons from this study have also been presented at several national and international workshops and conferences. 


\section{REFERENCES}

Berry, N. 2006. "Kaqchikel midwives, home births, and emergency obstetric referrals in Guatemala: Contextualizing the choice to stay at home", Social Science \& Medicine. 62: 8, pp. 1958-1969.

De Brouwere, V., Tonglet, R. \& W. Van Lerberghe. 1998. "Strategies for reducing maternal mortality in developing countries: what can we learn from the history of the industrialized West?” Trop Med Int Health 1998, 3:771-782.

Central Bureau of Statistics, Ministry of Health, and ORC Macro. 2004. Kenya Demographic and Health Survey 2003. Calverton, Maryland: CBS, MOH, and ORC Macro.

Koblinsky, M., Campbell, O. \& J. Heichelheim. 1999. "Organizing delivery care: what works for safe motherhood?” Bull World Health Organ, 77: 399-406.

Ministry of Health. 2006. Taking the Kenya Essential Package for Health to the Community; A Strategy for the Delivery of Level One Services Ministry of Health: Nairobi, Kenya.

Population Council MOH \& UoN. 2004. Safe Motherhood Demonstration Project, Western Province: Approaches to providing quality maternal care in Kenya. Population Council: Nairobi, Kenya.

Population Council. 2006. Community Midwifery Implementation Guidelines in Kenya. Population Council: Nairobi, Kenya.

Ray, A.M. \& H.M. Salibu. 2004. "The impact of maternal mortality interventions using traditional birth attendants and village midwives". J Obstet Gynaecol. 24: 5-11.

Rolfe B, S. Leshabari, F. Rutta and S. Murray. 2008. "The crisis in human resources for health care and the potential of a 'retired' workforce: case study of the independent midwifery sector in Tanzania Health Policy and Planning 2008 23(2): 137 - 149

Rumbold, V. 2006. Cultural beliefs and practices influencing maternal and newborn health in Western Province, Kenya. Population Council: Nairobi, Kenya.

Rumbold, V. and Warren, C. 2006. A Review of the Community Midwifery Pilot Initiative in Western Province, Population Council: Nairobi, Kenya.

Sibley, L.M., Sipe, T.A. \& M. Koblinsky. 2004. "Does traditional birth attendant training increase use of antenatal care? A review of the evidence", J Midwifery Women's Health. 49: 298-305.

UNICEF \& Save the Children. 2005. Partnerships with Mothers, Families and Communities: Why working in partnerships with mothers, families and communities is essential to reduce maternal, newborn and child deaths, particularly in high mortality settings. Save The Children Federation, Inc. 
Van Eijk, A. et al. 2006. "Use of antenatal services and delivery care among women in rural western Kenya: a community based survey”, Reproductive Health. Vol. 3: 2.

Winch P, K. Gilroy, C. Wolfheim, E. Starbuck, M. Young, L. Walker, and R. Black. 2005. "Intervention models for the management of children with signs of pneumonia or malaria by community health workers", Health Policy and Planning. 20: 4, pp. 199-212.

World Health Organization. 2004. Making pregnancy safer: the critical role of the skilled attendant: a joint statement by WHO, ICM and FIGO. World Health Organization: Geneva, Switzerland.

World Health Organization. 2006. Skilled Attendant at |Birth: 2006 updates. www.who.int/reproductive-health.

White, P. and L. Levin. 2006. The Potential of Private Sector Midwives in Reaching the Millennium Development Goals, PSP-One Project, Abt Associates: Bethesda, USA.

World Health Report. 2006: WorkingTogether for Health. World Health Organization; Geneva, Switzerland. 


\section{ANNEX 1: Process for implementing the community midwifery model}

The diagram below illustrates the three-phased implementation process:

Planning and start up (phase 1); Introduction of interventions (phase 2); monitoring, evaluation and scale up (phase 3 ).

A. Rapid Assessment of maternal and newborn health and services available in the community/catchment area. Where do the majority of the deliveries take place?

Who assist women during childbirth? What are the distances, terrain, transport and communication to the facility? What hinders optimum utilization of the health facility? Are there professional midwives in the community? Any costs to implement and sustain community midwifery? What challenges are likely to occur? These should be written up into short report./development plan.

B. Reach consensus: Present findings of assessment and plans at district stakeholders' meeting. This should include DRH, PHMT, DHMT/DHMB, development partners, facility in-charges, facility development committees, Community health committees, CBOs FBOs, provincial administration and others

C. Identification and selection of professionals in the community with midwifery knowledge and skills (retired, out of work, private midwives).

D. Interventions These include refresher /updates on maternal and newborn care for efficiency. This includes a two-week program on theory and clinical attachment, provision of initial supply of consumables, basic equipment and stationary.

E. Follow up and supervision: Closely monitor the activities of the community midwife and assist in problem solving through the community system. Health facility in-charge, VHC, DHMT.

F. Monitoring and Evaluation: Use of documentation outlined in the $\mathrm{MOH}$ Community Strategy for Level One Services. Periodic evaluation of the effect community midwifery through in-depth interviews and FGDS with users and providers.

G. Sustainability mechanisms: Support for CMs should be integrated into District Annual Operational Plans, which will lead to incorporation into the national health plan and ultimately the SWAp funding mechanism. This will ensure CM equipment, supplies, administrative support and communication and include stipend for CM services. 


\section{ANNEX 2: $\quad$ Sample Business Plan for community Midwives}

BACKGROUND: To prepare your own business plan, answer the following questions as honestly as possible. If you find it difficult to answer any question immediately, it means that you have to look for more information regarding the business you intend to start or expand.

\subsection{HISTORY AND BACKGROUND OF THE BUSINESS}

\section{NAME OF THE OWNER OF THE BUSINESS:}

The Name of the business shall be:

I will operate this business:- (i) Alone [ ] (ii) Jointly with others [ ]

I will operate the business in Market/School/Church/ Mosque. shopping/market centre or near

My business will involve providing the following services:

My services are unique or different from those of my competitors because of the following reasons:-

My objectives for the business for the first year are:-

To get about customers who are currently buying from other business people

To make a profit of Ksh........... Every Month, Week or Day (Circle the right one)

To improve the quality of my products or services (Please explain).

Other (Please specify)

2.0 MARKETING PLAN

2.1 OVERALL, I EXPECT TO SELL MY PRODUCTS OR SERVICES TO THE FOLLOWING KIND OF CUSTOMERS (INDIVIDUALS OR BUSINESSES)

approximate number approximate number 
Each one of them buys about times per* Month /Week/Day.

I have estimated sales for the different products or services per Month//Week/Day to be as follows:-

\begin{tabular}{|l|c|c|c|c|}
\hline Goods or Services & $\begin{array}{c}\text { Quantity } \\
\text { (No.) }\end{array}$ & $\begin{array}{c}\text { Selling } \\
\text { Price per } \\
\text { item }\end{array}$ & $\begin{array}{c}\text { TOTAL } \\
\text { (Kshs.) }\end{array}$ \\
\hline 1 & & & & \\
\hline 2 & 3 & & & \\
\hline 4 & & & & \\
\hline 5 & & & \\
\hline \multicolumn{2}{|l|}{ TOTAL (Kshs.) } & & & \\
\hline
\end{tabular}

I expect to reach the following level of sales per month for the first one year

\begin{tabular}{|c|c|c|c|c|c|c|c|c|c|c|c|c|c|}
\hline & \multicolumn{10}{|c|}{ M O N T H } & Total \\
\cline { 2 - 14 } & 1 & 2 & 3 & 4 & 5 & 6 & 7 & 8 & 9 & 10 & 11 & 12 & (Kshs) \\
\hline Sash Sales & & & & & & & & & & & & & \\
\hline Credit sales & & & & & & & & & & & & & \\
\hline Total (KShs) & & & & & & & & & & & & & \\
\hline
\end{tabular}

\subsection{MY MAJOR COMPETITORS}

Some of the important business people operating businesses similar to mine are :-

\begin{tabular}{|l|l|l|l|}
\hline & COMPETITOR & COMPETITOR'S STRENGTHS & $\begin{array}{l}\text { HOW I WILL OUT-COMPETE } \\
\text { THEM }\end{array}$ \\
\hline 1 & & $\overline{-}$ & - \\
\hline 2 & & $\overline{-}$ & \\
\hline 3 & & $\overline{-}$ & $\overline{-}$ \\
\hline
\end{tabular}




\subsection{PRODUCTION /OPERATIONS PLAN}

3.1 PRODUCTION / OPERATION PROCESS

The major steps or stages in the production or operations of my business are as outlined below:-

\begin{tabular}{|l|l|l|}
\hline & STEP/STAGE & CRITICAL / IMPORTANT THINGS TO BE CAUTIOUS ABOUT \\
\hline 1. & & \\
& & \\
\hline 2. & & \\
\hline 3. & & \\
\hline
\end{tabular}

\subsection{EQUIPMENT, TOOLS, AND OTHER FIXED ASSETS REQUIRED}

The equipment, tools, and other fixed assets required to operate the business are as listed below.

\begin{tabular}{|l|l|l|l|l|l|}
\hline & Equipment /Tool & Quantity & Supplier & $\begin{array}{c}\text { Buying Price Per item } \\
\text { (KShs) }\end{array}$ & $\begin{array}{c}\text { TOTAL } \\
\text { (Kshs) }\end{array}$ \\
\hline 1. & & & & & \\
\hline 2. & & & & & \\
\hline 3. & & & & & \\
\hline 4. & & & & \\
\hline 5. & & & & \\
\hline
\end{tabular}

\subsection{FINANCIAL PLAN}

\subsection{DIFFERENT COSTS}

Buying fixed Assets (refer to Section 3.2) $=$ Kshs.

Pre-operational Costs [These are costs which will be incurred before starting the business]

\begin{tabular}{|l|c|c|}
\hline & ITEM & COST (Kshs) \\
\hline 1 & & \\
\hline 2 & & \\
\hline 3 & & \\
\hline 4 & & \\
\hline \multicolumn{2}{|l|}{ TOTAL (Kshs) } & \\
\hline
\end{tabular}


Costs of running the business for at least one month.

After closely considering the business that I will start --- [i.e. after discussing it with other group members, members of my family, neighbors and friends, business people, and the potential buyers] ---- I have determined that the total costs of running my business for one month will be as I have written below.

\begin{tabular}{|l|l|l|}
\hline & \multicolumn{1}{|c|}{ EXPENSES } & TOTAL Kshs \\
\hline 1. & Purchase of goods for sale or materials for production or service provision & \\
\hline 2. & My own salary & \\
\hline 3. & Salary for employees & \\
\hline & & \\
\hline 4. & Security & \\
\hline 5. & Transport & \\
\hline 6. & Rent - for business premises & \\
\hline 7. & Electricity/ Fuel / Firewood & \\
\hline 8. & Business promotion & \\
\hline 9 & Savings & \\
\hline 10 & Loan Repayment (where applicable) & \\
\hline 11. & Any other & \\
\hline TOTAL (Kshs ) & \\
\hline
\end{tabular}

\subsection{TOTAL MONEY REQUIRED TO START THE BUSINESS}

As per the costs I have identified above (4.1), the total money required to start the business is:-

4.1 (a) Ksh. +4.1 (b) Ksh. 4.1 (c) Ksh. $=\mathrm{Ksh}$

\subsection{WILL GET THAT MONEY FROM THE FOLLOWING SOURCES:}

\begin{tabular}{|l|l|l|}
\hline & \multicolumn{1}{|c|}{ SOURCE } & TOTAL (Ksh) \\
\hline 1 & From my own pocket & \\
\hline 2 & From my parents/guardians/spouse & \\
\hline 3 & Loan from:--- & \\
\hline 4 & Any other source & \\
\hline & TOTAL (Kshs.) & \\
\hline
\end{tabular}


4.4. PROJECTED CASH FLOW “IN” AND “OUT” FLOWS (i.e. Income and Expenditure)

\begin{tabular}{|c|c|c|c|c|c|c|c|c|}
\hline \multirow{2}{*}{\multicolumn{2}{|c|}{$\begin{array}{c}\text { IN } \\
(\text { CASH RECEIPT) }\end{array}$}} & \multicolumn{7}{|c|}{ MONTH } \\
\hline & & \multirow[t]{2}{*}{1} & \multirow[t]{2}{*}{2} & \multirow[t]{2}{*}{3} & \multirow[t]{2}{*}{4} & \multirow[t]{2}{*}{5} & \multirow[t]{2}{*}{6} & \multirow[t]{2}{*}{$\begin{array}{c}\text { TOTAL } \\
(\mathrm{Ksh})\end{array}$} \\
\hline 1 & $\begin{array}{l}\text { Balance from } \\
\text { last month }\end{array}$ & & & & & & & \\
\hline 2 & $\begin{array}{l}\text { My own pocket/ } \\
\text { investment }\end{array}$ & & & & & & & \\
\hline 3 & Loan from ------ & & & & & & & \\
\hline 4 & Cash sales & & & & & & & \\
\hline 5 & $\begin{array}{l}\text { Collection from } \\
\text { debtors }\end{array}$ & & & & & & & \\
\hline 6 & Others & & & & & & & \\
\hline \multicolumn{9}{|c|}{ TOTAL (Ksh) } \\
\hline \multicolumn{9}{|c|}{$\begin{array}{l}\text { OUT } \\
\text { (EXPENDITURE) }\end{array}$} \\
\hline \multicolumn{9}{|c|}{\begin{tabular}{l|l}
1 & \\
\end{tabular}} \\
\hline \multicolumn{9}{|l|}{2} \\
\hline \multicolumn{9}{|l|}{3} \\
\hline \multicolumn{9}{|l|}{4} \\
\hline \multicolumn{9}{|l|}{5} \\
\hline \multicolumn{9}{|l|}{6} \\
\hline \multicolumn{9}{|l|}{7} \\
\hline \multicolumn{9}{|l|}{8} \\
\hline \multicolumn{9}{|l|}{9} \\
\hline \multicolumn{9}{|l|}{10} \\
\hline \multicolumn{9}{|l|}{11} \\
\hline \multicolumn{9}{|l|}{12} \\
\hline \multicolumn{9}{|c|}{ TOTAL (b) } \\
\hline $\begin{array}{l}\mathrm{BA} \\
{[(\mathrm{a})}\end{array}$ & $\begin{array}{l}\text { LANCE c/f: } \\
\text { - (b)] }\end{array}$ & & & & & & & \\
\hline
\end{tabular}




\section{ANNEX 3: Monthly Summary Reporting Form: Community Midwifery}

Indicate month of data covered

Location

Sub-location-

Village.

Facility linked to

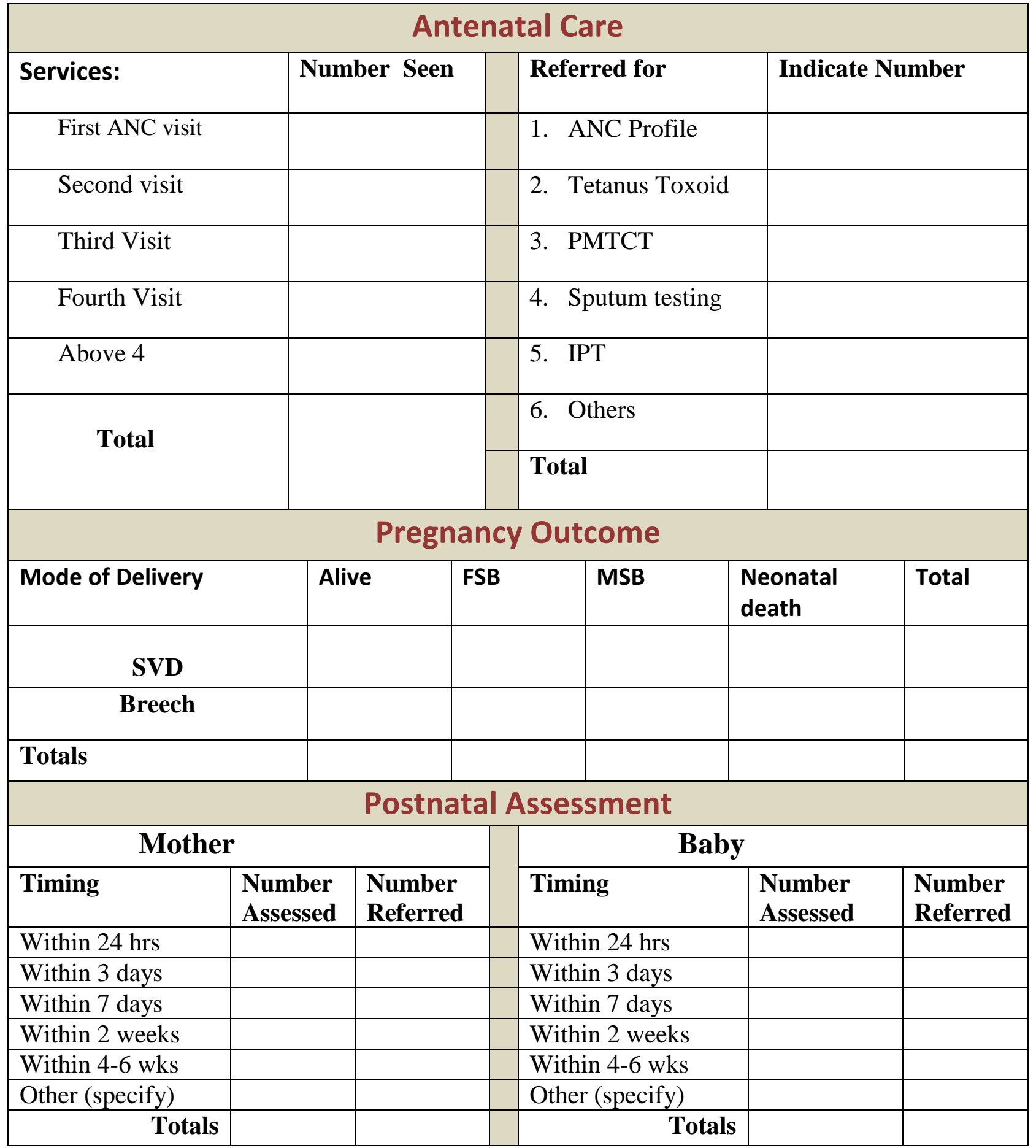




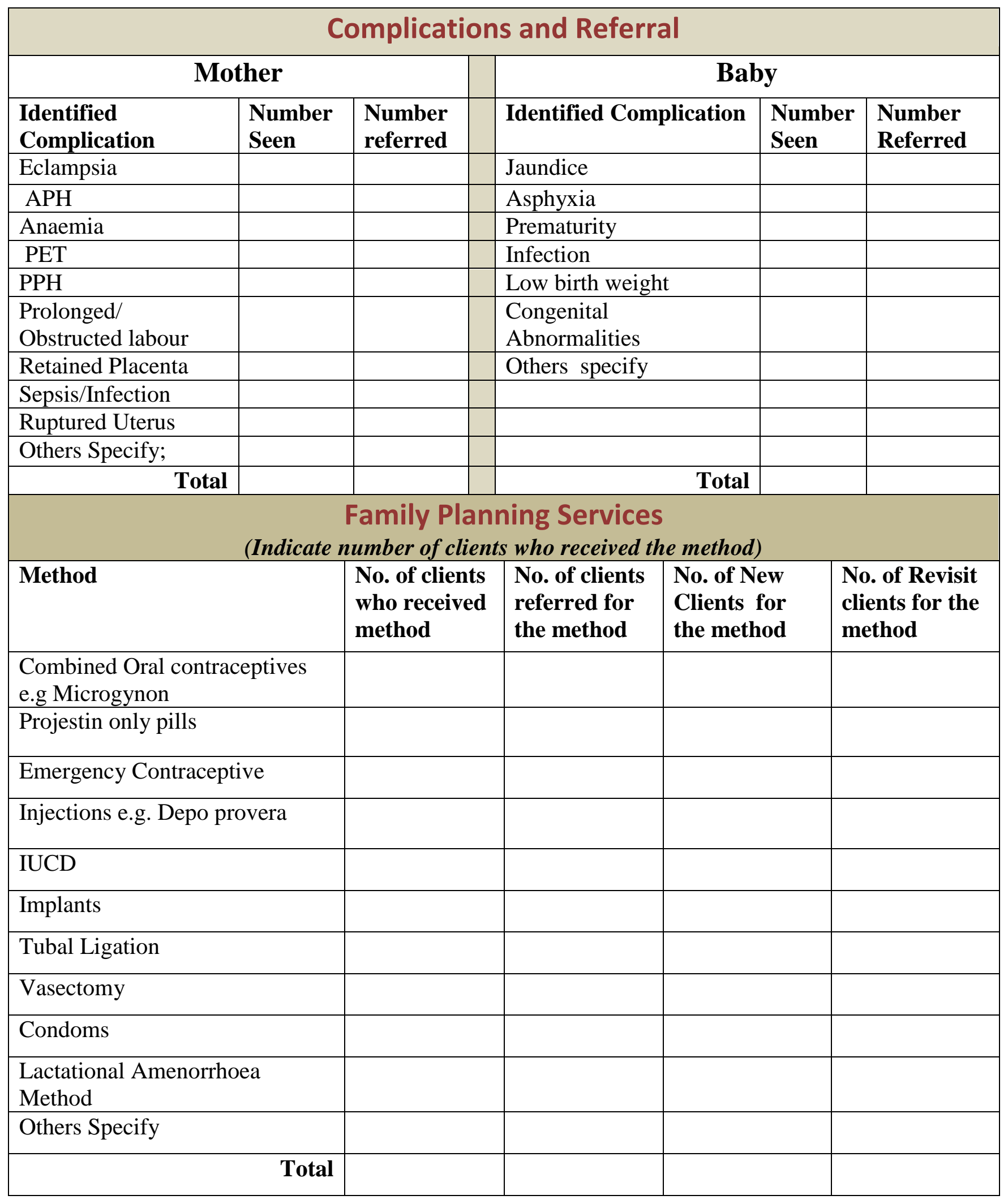

Report Compiled by (Midwife's Name)

Signature.

Date. 